University of Arkansas, Fayetteville

ScholarWorks@UARK

$5-2016$

\title{
The Effects of Brief, Passive Psychoeducation on Suicide Literacy, Stigma, and Attitudes Toward Help-Seeking Among Latino Immigrants Living in the United States
}

Aubrey Renee Dueweke

University of Arkansas, Fayetteville

Follow this and additional works at: https://scholarworks.uark.edu/etd

Part of the Clinical Psychology Commons, Latina/o Studies Commons, and the Multicultural Psychology Commons

\section{Citation}

Dueweke, A. R. (2016). The Effects of Brief, Passive Psychoeducation on Suicide Literacy, Stigma, and Attitudes Toward Help-Seeking Among Latino Immigrants Living in the United States. Graduate Theses and Dissertations Retrieved from https://scholarworks.uark.edu/etd/1446

This Thesis is brought to you for free and open access by ScholarWorks@UARK. It has been accepted for inclusion in Graduate Theses and Dissertations by an authorized administrator of ScholarWorks@UARK. For more information, please contact scholar@uark.edu. 
The Effects of Brief, Passive Psychoeducation on Suicide Literacy, Stigma, and Attitudes Toward Help-Seeking Among Latino Immigrants Living in the United States

\author{
A thesis submitted in partial fulfillment \\ of the requirements for the degree of \\ Master of Arts in Psychology
}

By

\author{
Aubrey Dueweke \\ Oberlin College \\ Bachelor of Arts in Psychology and Hispanic Studies, 2012
}

May 2016

University of Arkansas

This thesis is approved for recommendation to the Graduate Council.

Dr. Ana J. Bridges

Thesis Director

Dr. Matthew T. Feldner

Dr. Scott H. Eidelman

Committee Member

Committee Member 


\begin{abstract}
Latino immigrants drastically underutilize mental health treatment services compared to other ethnic groups, despite rates of mental illness that are comparable to those observed among the general population. With regards to suicidal behavior specifically, twice as many Latino suicide attempters do not seek or receive psychiatric services in the year prior to attempting suicide, compared to non-Latino White attempters. The main objective of this study was to investigate whether provision of brief, passive psychoeducation in the form of a brochure could increase suicide literacy (i.e., recognizing suicidal behavior, understanding risk factors and causes of suicidal behavior), reduce stigma toward suicidal behavior, and facilitate more positive attitudes toward help-seeking among a population of first generation Latino immigrants. It was hypothesized that the participants randomly assigned to the experimental group receiving psychoeducation regarding suicide would demonstrate greater suicide literacy, less suicide stigma, and more positive attitudes toward help-seeking than participants randomly assigned to the control group receiving psychoeducation about exercise. Results revealed that, while psychoeducation did significantly increase suicide literacy, it was not effective at changing stigmatizing attitudes towards suicidal individuals or improving attitudes toward seeking professional psychological help. However, lower levels of stigma were associated with more positive attitudes toward seeking help. These findings support the potential for a brief educational intervention to increase literacy among this population, but raise questions about how to effectively reduce stigma and improve attitudes toward treatment-seeking.
\end{abstract}




\section{Acknowledgements}

Special thanks are extended to Kate McGinnis and Angelica Perez-Bejar for all of their help with data collection for this project. I would also like to thank Dr. Ana Bridges for her continued guidance and support. I could not have done it without all of you! 


\section{Table of Contents}

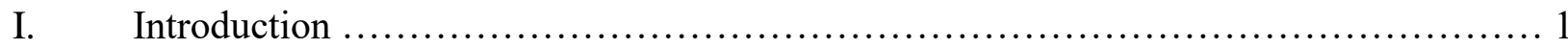

A. Suicidal Behavior Among Latino Immigrants.......................................

B. Underutilization of Mental Health Treatment by Latino Immigrants.......................

C. Health Belief Model............................................................

D. Modifying Socio-Cultural Factors...................................................

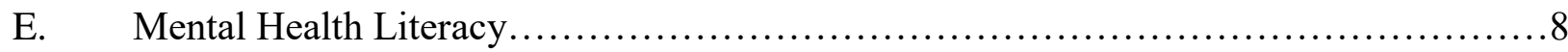

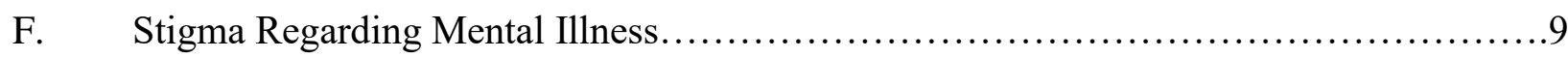

G. Stigma Regarding Suicidal Behavior.......................................... 10

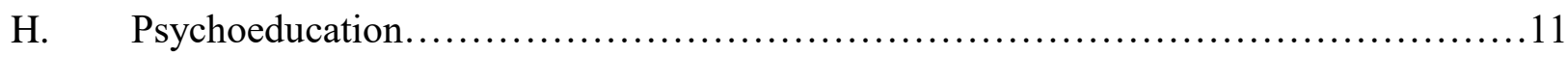

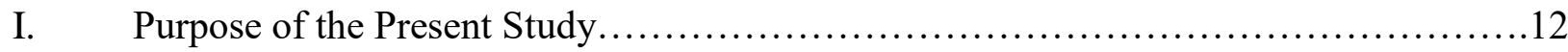

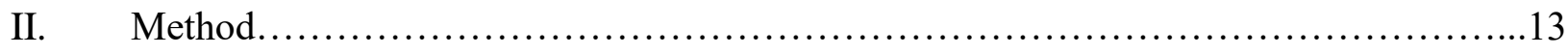

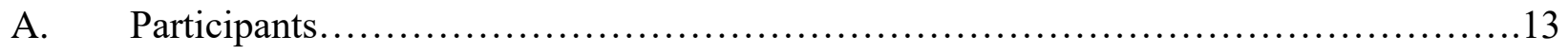

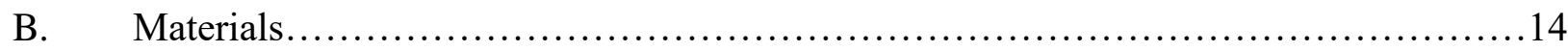

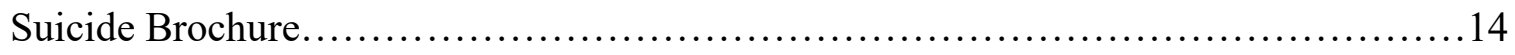

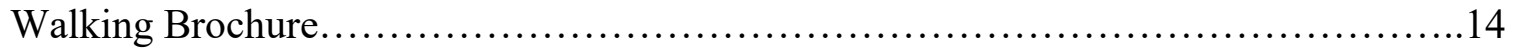

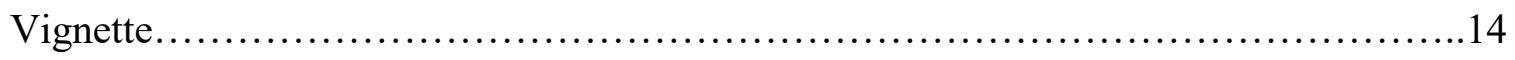

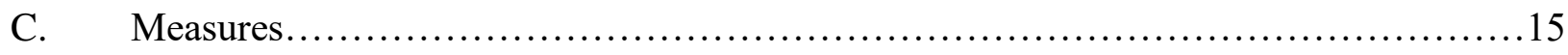

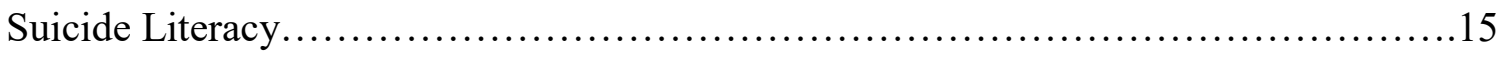

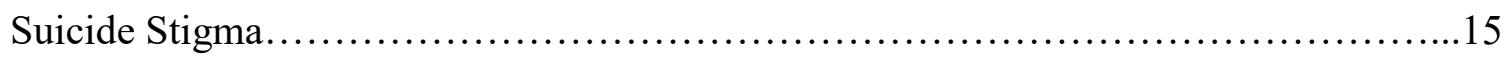

Attitudes Toward Help-Seeking..............................................17

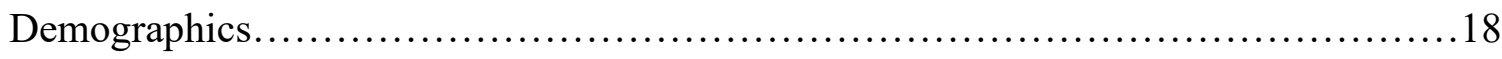

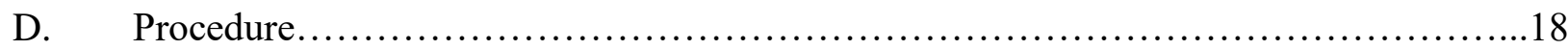




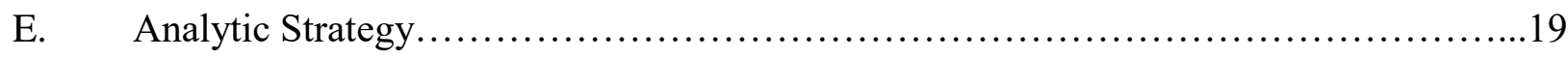

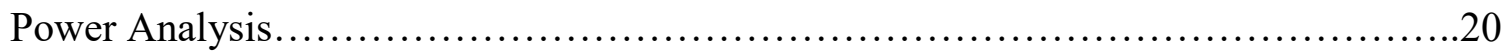

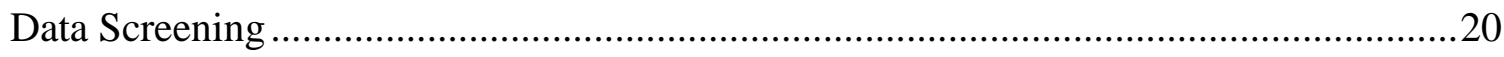

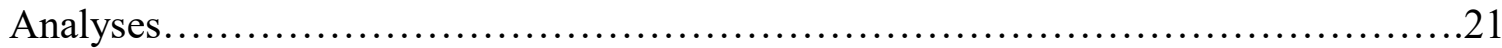

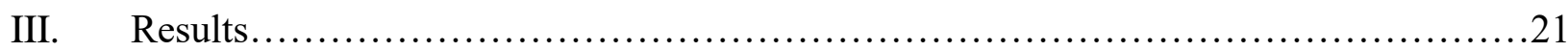

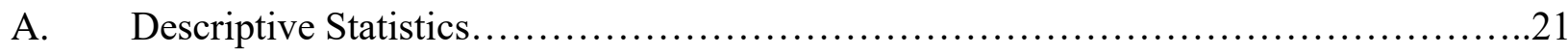

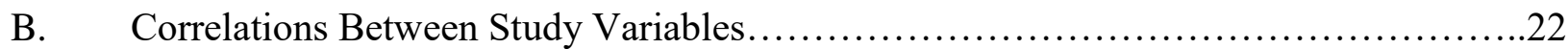

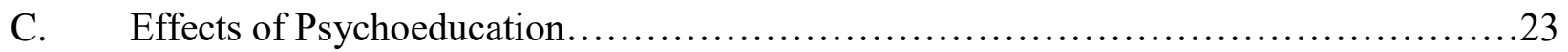

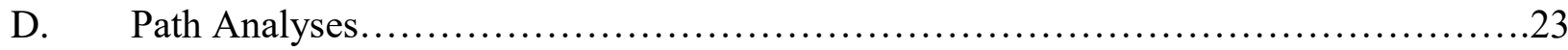

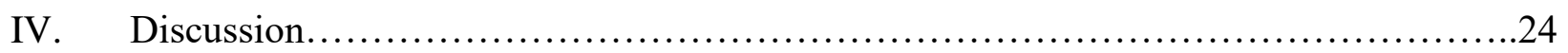

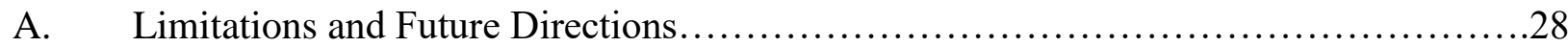

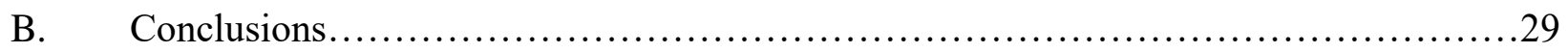

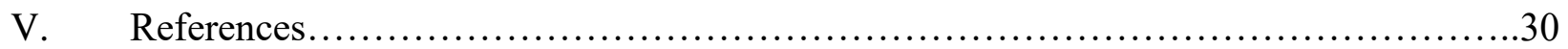

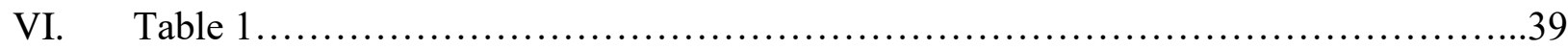

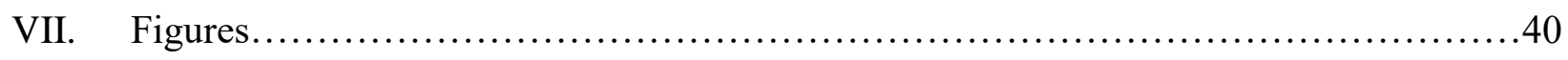

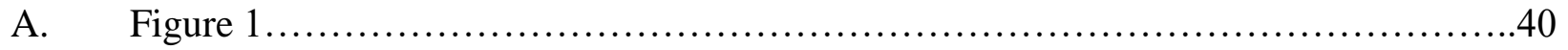

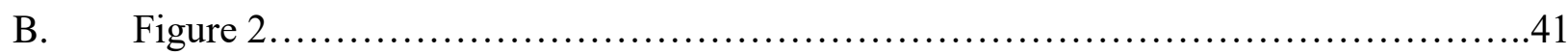

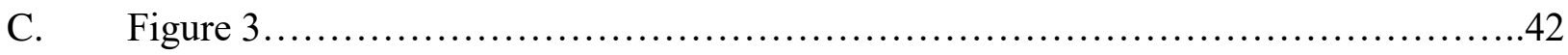

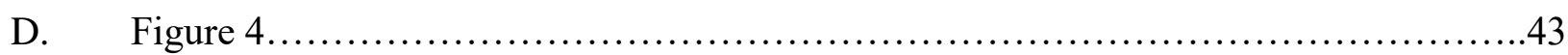

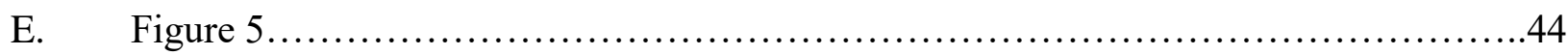

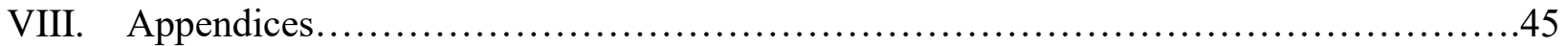

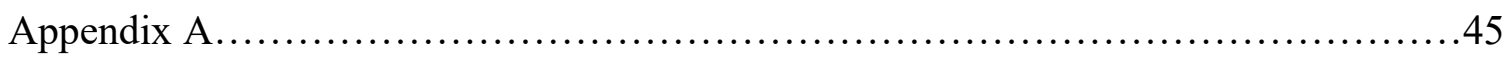

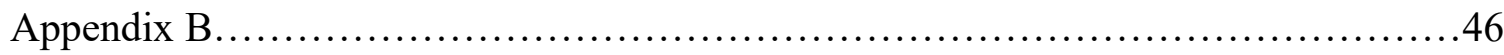


Appendix C.......................................................... 47

Appendix D................................................................... 48

Appendix E...........................................................49

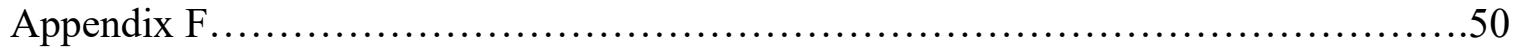

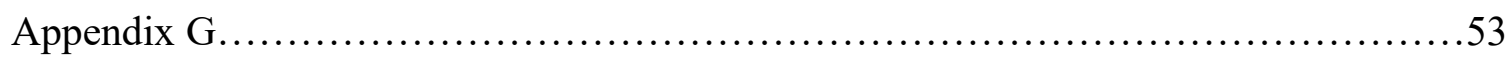



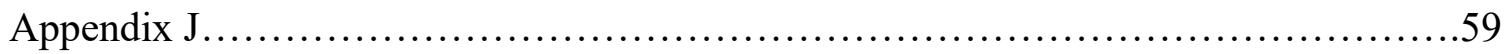

Appendix K...........................................................60

Appendix L.................................................................. 61 


\section{Introduction}

The number of immigrants living in the United States has been increasing significantly over the past few decades. There are approximately 39.9 million immigrants living in the U.S. today, which make up about $12.7 \%$ of our total population. Over $50 \%$ of these immigrants are Latinos $^{1}$ (Migration Policy Institute, 2011). In fact, estimates indicate that the Hispanic population living in the U.S. will constitute approximately $30 \%$ of the national population by the year 2050 (U.S. Census Bureau, 2010). In spite of the rapidly growing presence of Latinos in the U.S., prejudice and discrimination against this group persist in today's society (Pérez, Fortuna, \& Alegría, 2008). Latino immigrants may be at an elevated risk for experiencing mental health problems as a result of the strains placed on them by discrimination and the process of navigating two different cultures (Falcon \& Tucker, 2000; Finch, Hummer, Kolody, \& Vega, 2001).

Despite the large percentage of Latino immigrants residing in the U.S. and their added risk for experiencing mental health problems, relatively little research on immigrant mental health and treatment has been conducted (American Psychological Association, 2012).

\section{A. Suicidal Behavior Among Latino Immigrants}

In 2012, suicide was the third leading cause of death for Hispanic Americans aged 15 to 24 years and the fourth leading cause of death for those aged 25 to 34 years (Center for Disease Control and Prevention, 2012). The lifetime prevalence of suicidal ideation among Latinos has been placed at $11.35 \%$, and the lifetime prevalence for suicide attempts among Latinos has been placed at 5.11\% (Borges, Orozco, Rafful, Miller, \& Breslau, 2012). Additionally, according to the 2011 National Survey of Drug Use and Health, 2.5\% of Latinos reported having had serious

\footnotetext{
${ }^{1}$ There has been much debate in the literature regarding use of the term "Latino" vs. the term "Hispanic". For the purpose of this paper, I will use the two terms interchangeably, guided by the original language of the work I am referencing.
} 
thoughts of suicide within the past year, $0.8 \%$ reported having made suicide plans, $0.5 \%$ reported having attempted suicide, and only $0.2 \%$ had received medical attention following a suicide attempt (Figure 1). Notably, when suicide rates are reported in fact sheets or described in the media, the numbers given often speak only to completed suicides. Thus, people may underestimate the prevalence rate for suicidal behavior. Although the nomenclature for describing completed suicide and suicidal ideation has been the subject of considerable debate (e.g., De Leo, Burgis, Bertolote, Kerkhof, \& Bille-Brahe, 2006; O’Carroll et al., 1996), suicidal behavior is generally understood to encompass a wide range of acts, including suicidal ideation, making a suicide plan, attempting suicide, and completing suicide (e.g., Gvion \& Apter, 2012; O’Connor, Gaynes, Burda, Williams, \& Whitlock, 2013). When the prevalence rates for these other behaviors are considered, it becomes apparent that suicidal behavior is in fact fairly common and a significant public health concern.

Some of the mental disorders most commonly associated with suicidal behavior are mood, schizophrenia, substance use, personality, and anxiety disorders (Bertolote \& Fleischmann, 2002; Mann, 2003). However, until the recent release of the fifth edition of the Diagnostic and Statistical Manual of Mental Disorders (DSM-5; American Psychiatric Association, 2013), suicidal behavior was considered to be primarily a symptom of a major depressive episode or borderline personality disorder (Oquendo et al., 2008). This was problematic because it created a situation in which clinicians were not explicitly guided by the DSM in the assessment of suicide risk if no evidence for major depression or borderline personality was identified. In other words, the diagnostic algorithms accompanying previous versions of the DSM allowed for situations in which clinicians might overlook suicidal ideation or behavior. Fortunately, the DSM-5 has taken steps to improve upon some of these issues, and 
suicidal behavior is now considered to be an independent entity that is related to a number of other mental disorders. Chapters throughout the DSM-5 now highlight particular characteristics that may heighten an individual's vulnerability to suicide, reflecting findings that suicidal behavior is not solely a concern for patients with mood or personality disorders. Additionally, a component of the new edition of the DSM called "Section III" includes a number of assessment tools that are designed to help clinicians evaluate patients in a comprehensive way, independent of specific disorders.

Previous research has shown that rates of suicidal behaviors among Latinos are similar to rates of suicidal behaviors observed in the general population (Borges et al., 2012; National Council of La Raza, 2005). However, findings regarding the relationship between immigrant status and suicidal behavior among a Latino population are mixed. While some studies have found that Latino immigrants have a slightly higher rate of completed suicide than nonimmigrants (e.g., Wadsworth \& Kubrin, 2007), others have found that U.S.-born Latinos have higher rates of suicidal ideation and attempts than Latino immigrants (e.g., Borges et al., 2012). Additionally, Borges and colleagues (2012) found that among foreign-born Latinos, those who had immigrated to the U.S. at age 12 or younger reported significantly higher levels of suicidal ideation and suicide attempts than those who had immigrated to the U.S. at age 13 or older. When exploring possible explanations for this finding, previous research has identified factors such as higher levels of perceived discrimination and lower Hispanic composition of social networks to be associated with an increased risk for suicidal ideation and attempts among Latino immigrants living in the U.S. (Perez-Rodriguez et al., 2014).

\section{B. Underutilization of Mental Health Treatment by Latino Immigrants}


Despite evidence suggesting that Latino immigrants may be at an elevated risk for developing internalizing disorders (Falcon \& Tucker, 2000; Finch et al., 2001), and possibly engaging in suicidal ideation and behavior (Wadsworth \& Kubrin, 2007), Latinos living in the U.S. have been shown to dramatically underutilize mental health services compared to other ethnic groups (Alvidrez, 1999; Sue, Fujino, Hu, Takeuchi, \& Zane, 1991; Vega, Kolody, Aguilar-Gaxiola, \& Catalano, 1999). Some of the most robust findings of Latino Americans' underutilization of mental health services are from the National Latino and Asian American Study (NLAAS; Alegría et al., 2008), the Los Angeles site of the Epidemiologic Catchment Area Study (LA-ECA; Burnham, Hough, Karno, Escobar, \& Telles, 1987), and the Mexican American Prevalence and Services Study (MAPSS; Vega et al., 1998). Results from the NLAAS indicate that $63.6 \%$ of Latinos, compared with $40.2 \%$ of non-Latino Whites, did not access any mental health treatment in the year prior to the study (Alegría et al., 2008). Similarly, results from the LA-ECA study indicate that non-Hispanic Whites are seven times more likely to use outpatient mental health services than Mexicans living in the U.S. who speak mostly Spanish, and that Mexicans who are less acculturated have very low use of any professional services (Burnham et al., 1987). Moreover, within the Latino population, immigrants with a diagnosable mental disorder are the least likely to use mental health services (Hough et al., 1987; Vega et al., 1999). For instance, the MAPSS study found that Mexican American immigrants use only $40 \%$ of the services that U.S.-born Mexican Americans do (Vega et al., 1998).

This pattern of underutilization of mental health treatment holds with regard to suicidal Latino Americans. For example, the 2008-2009 National Survey on Drug Use and Health found that Latino adults who reported engaging in suicidal thoughts or attempts were less likely than non-Latino Whites to seek or receive psychiatric services (Ahmedani et al., 2012). In fact, 
$45.7 \%$ of Hispanic suicide attempters reported that they did not seek or receive psychiatric services in the year prior to attempting suicide, compared to $24.1 \%$ of non-Latino White attempters (Suicide Prevention Resource Center, 2013). Furthermore, Latinos are less likely than other ethnic groups to call a crisis line during a suicidal crisis (Larkin, Rivera, Xu, Rincon, \& Beautrais, 2011).

Consistent with patterns found among the general population (e.g., Deen \& Bridges, 2011), Latino immigrants' preferences are to rely on informal sources of care (e.g., family member, friend, priest) before turning to formal sources of care (e.g., social worker, doctor, psychiatrist) to cope with mental health problems (Cabassa \& Zayas, 2007; Guarnaccia, Martinez, \& Acosta, 2005). Additionally, previous research has shown that Latinos with mental health problems are more likely to seek help from a general practitioner than from a mental health professional (Dwight-Johnson et al., 2010; Vega et al., 1999). For example, DwightJohnson and colleagues (2010) found that among a sample of depressed Latino patients taken from a primary care clinic, participants preferred treatment in primary care to specialty mental health care. Unfortunately, even when Latinos do seek help from a mental health professional, they are fairly likely to prematurely discontinue treatment (Santiago-Rivera et al., 2010; Sue et al., 1991). There are numerous conceptual models in the existing literature that attempt to explain the diverse array of factors that may influence an individual's decision to seek mental health treatment. Perhaps one of the most influential of these models is the health belief model (Rosenstock, Strecher, \& Becker, 1988), described next.

\section{Health Belief Model}

The health belief model (Rosenstock et al., 1988) was originally proposed to aid in the exploration of different factors that lead to the use of health services. The health belief model 
proposes that a person's decision to engage in a health-related behavior, such as treatmentseeking, depends on that person's perceptions of his or her susceptibility to the disorder, the severity of the disorder, and the benefits of and barriers to taking action to reduce susceptibility to or severity of the condition (Figure 2). In order for an individual to take action, he or she must believe that the anticipated benefits of taking action outweigh the anticipated barriers (Rosenstock et al., 1988).

Numerous studies have sought to identify some of the practical barriers that may prevent Latino immigrants from seeking mental health treatment. The most commonly identified barriers to seeking care by Latino immigrants are lack of health insurance, inability to pay for services, language problems, and not knowing where to seek services (Cabassa \& Zayas, 2007; Guarnaccia et al., 2005). Other barriers that have been identified include inability to take time off of work, lack of childcare, lack of transportation, unemployment, and fear of deportation due to immigration status (Kouyoumdijian, Zamoanga, \& Hansen, 2003; Santiago-Rivera et al., 2010). In a previous study assessing mental health needs and service utilization patterns among a sample of Hispanic immigrants residing in Northwest Arkansas, the most common barriers to service utilization identified by participants were cost (59\%), lack of health insurance (35\%), and language (31\%) (Bridges, Andrews, \& Deen, 2012). In their attempt to identify effective barrier reduction strategies for Latino immigrants, Dwight-Johnson and colleagues (2010) found that individual education sessions, telephone sessions, transportation assistance, and inclusion of the family in a treatment plan were all barrier reduction strategies that would enhance Latinos' likelihood of accepting mental health treatment. Although these findings are noteworthy, there is still much we do not know about the set of specific factors that may be related to Latinos staying in treatment or dropping out prematurely (Santiago-Rivera et al., 2010). Relatively few studies 
have examined Latino immigrants' perceptions of the potential benefits to seeking mental health treatment. Results from Cabassa and Zayas' (2007) study demonstrated a positive association between patients' perceptions that their doctors would listen to them and act in their best interest and their likelihood of seeking help from professional providers, indicating that the formation of a trusting patient-provider alliance seems to be of the utmost importance among this population.

Inherent in the health belief model is the idea that the four constructs (i.e., perceived susceptibility, perceived severity, perceived benefits, and perceived barriers) are all modified by other personal variables, such as culture, education level, and past experiences (Figure 2). Additionally, the health belief model posits that a person's behavior is influenced by external cues to action. Cues to action are events, people, or situations that push people to change their behavior. Examples include media reports, advice from others, and illness of a family member. Since its creation, the health belief model has grown to become one of the most commonly used conceptual models in research examining treatment-seeking behavior.

\section{Modifying Socio-Cultural Factors}

According to the health belief model, the combined perception of benefits and barriers to action is only one component determining an individual's likelihood of seeking care. The modifying effects of socio-cultural factors such as stigma and mental health literacy are also critical to understanding health behavior. For the purpose of this study, I aimed to examine the specific influences of stigma and mental health literacy on attitudes toward treatment-seeking. Stigma has been defined as the fostering of negative and often incorrect attitudes towards a particular group of people (Corrigan \& Penn, 1999). Mental health literacy refers to knowledge about mental disorders and includes the ability to recognize specific disorders, knowledge and beliefs about risk factors and causes, and attitudes that facilitate recognition and help-seeking 
behavior (Jorm, 2000). Both lower levels of mental health literacy and higher levels of stigma have been identified as factors that may prevent appropriate help-seeking behavior (Barney, Griffiths, Jorm, \& Christensen, 2006; Corrigan, 2004; Jorm, 2000; Link \& Phelan, 2006). Although various studies have identified potential practical barriers that may explain the pattern of underutilization of mental health care services among Latino immigrants, fewer studies have assessed the role of socio-cultural modifying factors such as mental health literacy and stigma on attitudes toward help-seeking among Latino immigrants.

\section{E. Mental Health Literacy}

Very few studies have investigated levels of mental health literacy among a Latino immigrant population. Furthermore, to my knowledge, all of the existing studies that have investigated mental health literacy among a Latino population have only looked at knowledge of depression specifically. Thus, further research is needed to investigate levels of mental health literacy among Latino immigrants with regard to other mental health problems, such as anxiety and suicidal behavior. Notably, the few studies that have looked at depression literacy among this population have found that Latino immigrants tend to have low depression literacy rates. For example, in one study by Cabassa (2007), 56 Latino immigrant men were presented with a vignette depicting an individual suffering from major depression. They struggled to accurately identify the condition - only $39 \%$ of the participants described the vignette as depression, while others described as a debilitating condition caused by social stressors that would improve with time. However, this low rate of depression literacy among Latino men is consistent with the low depression literacy rates exhibited by non-Latino Whites. For example, Deen and Bridges (2011) found that among a sample of rural White men, only $35 \%$ were able to correctly identify depression using the same vignette methodology employed by Cabassa (2007). Depression 
literacy rates among mixed gender samples were found to be similar between Latinos and nonLatino Whites as well; in Cabassa's study (2007) 55\% of a sample of Hispanic immigrant patients demonstrated depression literacy, while in Deen and Bridges's study (2011), only 53\% of a sample of rural White Americans demonstrated depression literacy. In addition, in Cabassa's study (2007), almost all of the participants reported that they would prefer counseling over medication treatments and many reported misconceptions about the effects of antidepressant medications. Sixty-one percent of the participants agreed that antidepressants were addictive, and $41 \%$ had strong convictions that they made people feel drugged (Cabassa, 2007). As stated above, additional research is needed to gain a better understanding of levels of mental health literacy among a Latino immigrant population.

\section{F. Stigma Regarding Mental Illness}

Previous research has shown that both having a mental illness and seeking mental health treatment are highly stigmatized among many Latinos (Interian et al., 2010; Vega, Rodriguez, \& Ang, 2010). In a study by Marquez and Ramirez García (2013), Mexican caregivers who were responsible for adult relatives with a serious and persistent mental illness reported lack of family support, stigma, and cultural beliefs such as vergüenza (shame) and negación (denial) as barriers to seeking formal treatment in a mental health facility. One caregiver stated, "Mexican families are afraid to look for services because they are worried about what others will say. We have been raised to have shame if there is illness in the family so we hide it." (Marquez \& Ramirez García, 2013, p. 405). In another study, Nadeem and colleagues (2007) aimed to examine the extent to which stigma-related concerns about mental health care account for the underutilization of mental health treatment services among low-income immigrant and U.S.-born Black and Latina women. Interestingly, they found that stigma reduced the desire for mental health 
treatment for immigrant women with depression to a greater extent than it did for U.S.-born White women with depression. Due to the limited number of available studies, further research is needed in order to clarify the nature of the effects of stigma on mental health treatmentseeking behavior among Latino immigrants.

\section{G. Stigma Regarding Suicidal Behavior}

Suicidal behavior is highly stigmatized. In fact, evidence for judgment against suicidal behavior dates back to the fourth century. Negative attitudes toward suicidal behavior intensified with the rise of Christianity, as suicide is considered unacceptable within Christian values (Tadros \& Jolley, 2001). To this day, there continues to be a strong association between Christian religious values and disapproval of suicidal behavior. Although this association may serve as a protective factor against completed suicide among a highly religious population (Hovey, 1999; Sorenson \& Golding, 1988), higher stigma surrounding suicidal behavior is generally considered harmful, as it may discourage people from talking about their suicidal thoughts or seeking necessary professional help for fear of being labeled as weak, lacking faith, coming from bad families, or being labeled 'mad'. In fact, some evidence suggests that as many as $68 \%$ of people who complete suicide have no contact with mental health services in the year before suicide (Luoma, Martin, \& Pearson, 2002). Little research has specifically examined why those at risk for suicide do not seek help, but in general, it has been shown that stigmatizing attitudes toward people with mental illness may reduce appropriate help-seeking (Link \& Phelan, 2006). Thus, it is reasonable to assume that decreasing stigmatizing attitudes toward suicidal behavior may lead to increased openness to help-seeking among those who are at risk for suicide.

The existing literature is greatly lacking with regard to research that assesses the extent to which suicide stigma is a barrier to help-seeking and attempts to determine whether intervention 
programs are effective in decreasing this stigma (Batterham, Calear, \& Christensen, 2013a). In particular, intervention studies are needed to determine whether suicide literacy and attitudes toward suicidal behavior can be modified in a community sample, and whether such modifications can result in more positive attitudes toward help-seeking. As such, increasing help-seeking and referrals for individuals at risk for suicide by decreasing stigma has been defined as a key aspirational goal in the National Action Alliance for Suicide Prevention's Research Prioritization Task Force's 2014 prioritized research agenda (National Action Alliance for Suicide Prevention, 2014).

\section{H. Psychoeducation}

Previous research suggests that in general, psychoeducational interventions can lead to reduced stigma surrounding mental health issues and increased mental health literacy (Corrigan \& Penn, 1999; Griffiths, Christensen, Jorm, Evans, \& Groves, 2004; Jorm et al., 2003). Psychoeducational interventions are defined as those that offer information regarding mental disorders to individuals with the intention of changing behavior (Donker, Griffiths, Cuijpers, \& Christensen, 2009). Psychoeducation can be categorized as either passive or active. Donker and colleagues (2009) have explained that passive psychoeducation, which can be offered through leaflets, posters, audio-visual aids, lectures, internet material or software, does not require specific action on the part of the recipient. Conversely, active psychoeducation requires the recipient to undertake explicit homework or exercises, and is often delivered in the context of treatment.

Although many studies have assessed the effectiveness of active, in-person psychoeducation (Lukens \& McFarlane, 2004), fewer studies have investigated the effectiveness of brief, passive psychoeducation (Donker et al., 2009). This trend in the literature is 
unfortunate, since brief, passive psychoeducation is common, as it is much easier and less expensive to provide than active psychoeducation and treatment. Certainly, further research on the effectiveness of different forms of psychoeducation delivered across various settings is critical. Lukens and McFarlane (2004) supported this claim, and added that outcome measures of future investigations should assess the effects of psychoeducation on an individual's knowledge and attitudes toward the target disorder, as well as the individual's social functioning and selfefficacy. In other words, there are multiple variables of interest that can speak to the effectiveness of psychoeducation in improving a wide array of domains of functioning.

Little research has assessed whether provision of psychoeducation can be effective in suicide prevention (Batterham et al., 2013a). In particular, the existing literature on the subject suggests that suicide literacy and stigma reduction programs should target men, people of culturally diverse backgrounds, and those with lower levels of education (Batterham et al., 2013a). Given the low mental health literacy (Cabassa, 2007) and high levels of stigma surrounding mental illness and treatment-seeking (Interian et al., 2010; Vega et al., 2010) observed among Latino immigrants, as well as findings suggesting that low levels of mental health literacy and high levels of stigma can negatively influence an individual's attitudes toward treatment-seeking (Corrigan, 2004; Nadeem et al., 2007), it seems there is a clear need for studies examining the effects of providing psychoeducation to this population.

\section{Purpose of the Present Study}

As discussed above, previous research has shown that in general, mental health literacy is low among Latino immigrants and that mental illness, particularly suicidal behavior, is highly stigmatized among this group. Additionally, it has been shown that Latino immigrants drastically underutilize mental health treatment services compared to other populations. 
However, research examining the influences of suicide literacy (i.e., ability to recognize suicidal behavior, understanding of risk factors and causes of suicidal behavior) and suicide stigma on Latino immigrants' attitudes toward professional mental health treatment is still severely lacking. Guided by the health belief model, the current study posits that treatment underutilization by Latino immigrants may be partially explained by lower mental health literacy which, in turn, is associated with higher levels of stigma.

Due to the drastic underutilization of mental health services by Latino immigrants despite comparable rates of suicidal behaviors, research examining the effectiveness of brief passive psychoeducation regarding suicide for this population is imperative. If brief, passive psychoeducation can be successful at increasing suicide literacy, decreasing suicide stigma, and increasing positive attitudes toward treatment-seeking among Latino immigrants, it will have important clinical implications for the field of suicide prevention. Thus, this study aimed to examine whether suicide literacy, suicide stigma, and attitudes toward treatment-seeking could be modified in a Latino immigrant population through the provision of brief, passive psychoeducation on the topic of suicide. More specifically, I aimed to examine whether reading a brochure on the topic of suicide could increase suicide literacy, decrease suicide stigma and increase positive attitudes toward treatment-seeking (Figure 3). I hypothesized that the experimental group receiving psychoeducation regarding suicide would demonstrate greater suicide literacy, less suicide stigma, and more positive attitudes toward help-seeking than the control group receiving psychoeducation about exercise.

\section{Method}

\section{A. Participants}


A total of 80 first-generation, immigrant-origin Latino adults participated in the present study. The participants were recruited at five community events that took place in a mid-southern region of the United States between May 2 and October 17, 2015. The final sample consisted of 78 participants, because a significant proportion of responses were missing for two participants. Participants ranged in age from 21 to 70 years $(M=36.2, S D=9.9)$ and were $70.5 \%$ female. Eighty-five percent of the participants identified as Mexican, $8 \%$ identified as being from another country in Central America, 6\% identified as Puerto Rican, and 1\% identified as South American. Participants' time spent living in the United States ranged from 0.8 to 45 years $(M=$ $17.6, S D=9.0$ ). Eighty-six percent of the participants identified as Catholic. Only $64 \%$ of the participants had graduated from high school.

\section{B. Materials}

Suicide Brochure. The brochure detailing information about suicide was a National Institute of Mental Health publication (U.S. Department of Health and Human Services, 2010) that included information on prevalence statistics, risk factors, prevention methods, and crisis help lines for suicide (Appendix A). It was available in both English and Spanish from the publisher.

Walking Brochure. The brochure detailing information about walking was a WeightControl Information Network publication (U.S. Department of Health and Human Services, 2014) that included information on stretches that can be performed prior to walking, a sample walking routine, and the potential health benefits of walking (Appendix B). It was available in English and Spanish from the publisher.

Vignette. A vignette describing a depressed individual who has recently attempted suicide was used to assess participants' levels of suicide literacy, suicide stigma, and attitudes 
toward seeking professional help. The vignette describes an individual who has been feeling depressed, has lost interest in things that once gave him pleasure, has lost touch with friends, feels like he is a burden on his family, and has recently tried to kill himself (Appendix C). Vignettes are commonly used to assess mental health literacy (e.g., Bridges, Karlsson, \& Lindly, 2014; Cabassa, 2007; Deen \& Bridges, 2011). In fact, this type of methodology been shown to be effective in assessing literacy among diverse populations such as rural Americans (e.g., Deen \& Bridges, 2011) and Latino immigrants (e.g., Cabassa, 2007). The vignette used in the current study was adapted from a depression vignette created by Deen and Bridges (2011).

\section{Measures}

Suicide Literacy. Participants' suicide literacy (i.e., knowledge of suicide) was assessed using the short form of the Literacy of Suicide Scale (LOSS) created by Calear, Batterham, and Christensen (2012). The short form of the LOSS consists of 12 true/false items assessing knowledge about suicide. For the purpose of this study, these items were reworded to pertain to the situation described in the vignette (Appendix D). Example items include, "[The person described in the vignette] will always be suicidal and entertain thoughts of suicide" and "Seeing a psychiatrist or psychologist may have helped prevent [the person described in the vignette] from trying to kill himself". Item response theory was used to identify items that had the strongest discrimination of the underlying literacy construct (Calear et al., 2012). The scale provides a total literacy score (percent correct), and can be broken down into three literacy themes: signs/symptoms, cause/nature, and treatment/prevention, for identification of individual strengths and weaknesses (Calear et al., 2012).

Suicide Stigma. Participants' desire for social distance from suicidal individuals was assessed using a revised version of the Social Distance Scale developed by Link and colleagues 
(1999). In this study, the Social Distance Scale includes five items that ask participants about their likelihood of interacting with the suicidal individual described in the vignette on a number of social levels (Appendix E). An example item is, "Would you spend an evening socializing with [the person described in the vignette]?" Possible responses to each item include $0=$ definitely not, $1=$ probably not, $2=$ probably, and $3=$ definitely. Scores on each item are summed to represent an overall social distance score, with lower scores indicating a greater desire for social distance from suicidal individuals. This is a commonly used measure of stigma surrounding mental illness, and it has been shown to have good to excellent internal consistency with Cronbach's alphas ranging from .75 to greater than .90 (Link et al., 2004). Additionally, the Social Distance Scale has been shown to have convergent validity with the Depression Stigma Scale $(r=.53)$. This measure has been used for Latino samples before, and has demonstrated adequate internal consistency in use with Latino samples (Cronbach's alpha $=.75)$. The Cronbach's alpha in the present study was .90 .

Participants' stigma surrounding suicide was also assessed using the short version of the Stigma of Suicide Scale (SOSS; Batterham et al., 2013b). For the purpose of this study, the SOSS was reworded so that the questions referred specifically to the suicidal individual described in the vignette, rather than assessing stigma towards people who die by suicide generally. The short version of the SOSS includes 16 items that can be rated on a 5-point rating scale $(1=$ strongly disagree to $5=$ strongly agree $)$. Three main aspects of suicide stigma are assessed within the SOSS: Stigma, Isolation/Depression, and Glorification/Normalization. Some example items include: "[the person described in the vignette's] attempt to commit suicide was shallow" and "[the person described in the vignette's] attempt to commit suicide was because he felt isolated". The SOSS demonstrates strong convergent validity with the Suicide Opinion 
Questionnaire, which also includes questions regarding the stigma, isolation, and acceptability of suicide. Additionally, the short version of the SOSS has adequate internal consistency $($ Cronbach's alpha $=.70)$. To my knowledge, this scale has yet to be tested among a Latino sample (Batterham et al., 2013a). Only the 8 items from the stigma subscale of the SOSS were utilized for the present study (Appendix F). The Cronbach's alpha for the present sample was .73. However, because the reliability of this stigma scale was much worse than that of the Social Distance Scale and it did not have any unique predictive value with any of the variables of interest (see correlations in Table 1), it was excluded from further analyses and only the Social Distance Scale was used to index stigma.

Attitudes Toward Help-Seeking. Participants' attitudes toward seeking care were assessed using a revised version of the Attitudes Toward Seeking Professional Psychological Help Scale - Short Form (ATSPPH-S; Fischer \& Farina, 1995). This inventory consists of 10 items that intend to measure participants' attitudes toward mental health treatment. For the purpose of this study, the questions were reworded so that they pertained specifically to the situation described in the vignette (Appendix G). Items are rated on a 4-point rating scale with response options ranging from $0=$ disagree to $3=$ agree. An example item is, "[The person described in the vignette] is not likely to solve his emotional problems alone; he is likely to solve them with professional help". Scores range from 0-30, with higher scores indicating more positive attitudes toward seeking psychological treatment. This measure has been shown to have good internal consistency for a Latino sample (Cronbach's alpha $=.83$; Rojas-Vilches, Negy, \& Reig-Ferrer, 2011), as well as adequate construct and criterion validity (Elhai, Schweinle, \& Anderson, 2008). In the present study, the Cronbach's alpha for the entire scale was .62. Followup analyses revealed that the reliability of the scale improved significantly upon deletion of the 
five reverse-scored items. As such, the five positively-worded items of the scale were the only items included in the analyses. The Cronbach's alpha for the revised scale was .80 .

Demographics. General demographic information about the background and current living circumstances of participants was also collected. A demographics form assessed participant age, sex, ethnicity, marital status, education, religious affiliation, amount of time living in the U.S., and financial strains (Appendix H). Participants' past help-seeking behavior was assessed with a question that asked whether they had experienced a problem similar to the scenario described in the vignette and, if so, whether they told a family member, friend, priest, doctor, or psychologist about their problem (Appendix J). Participants were asked to indicate how often they had thought about killing themselves in their lifetime, how many times they had ever attempted suicide and, if so, how much they wished to die during their most serious attempt (Appendix K). Participants' exposure to suicide was also assessed by way of a 10-level multiple choice item, with the highest level of exposure recorded out of no exposure (0), having observed suicide in a movie or television show (1), having watched a documentary on suicide (2), having had a colleague who attempted or died by suicide (3), having provided services to someone who attempted or died by suicide (4), having had an acquaintance who attempted or died by suicide (5), having had a relative who attempted or died by suicide (6), having had a close friend who attempted or died by suicide (7), having lived with someone who attempted or died by suicide (8), or having personally attempted suicide (9) (Appendix K).

\section{Procedure}

Potential participants were recruited from five regional community events. Inclusion criteria were such that participants had to self-identify as a first-generation Latino immigrant, be 18 years of age or older, and be fluent in either Spanish or English. From this convenience 
sample, participants were randomly assigned to either the control or the experimental condition. Participants in the experimental group received information from a brochure on suicide (Appendix A; U.S. Department of Health and Human Services, 2010), while participants in the control group received information from a brochure on walking (Appendix B; U.S. Department of Health and Human Services, 2014). Due to concerns about the functional literacy of the sample, all participants were also given the option to listen and follow along to a languagecongruent audio recording of the brochure. After receiving information from the brochure, all participants filled out a questionnaire packet that assessed their suicide literacy, stigma towards suicidal behavior, attitudes toward seeking treatment for suicidal behavior, past service utilization, current and past suicidal ideation, previous suicide attempts, exposure to suicide, and demographic information.

All measures that did not have a Spanish form available were translated to Spanish using the Brislin (1970) method. Specifically, bilingual researchers forward-translated and backtranslated each measure. Measures that were available in Spanish had been previously translated using a double-translation procedure, and had been found to be reliable and valid as above. Questionnaires were available in both Spanish and English.

Trained facilitators were on hand to read or clarify survey questions for individual respondents who required additional assistance. Consent forms were read and signed by individuals who wished to participate. Human subjects approval for these procedures from the institutional review board of the University of Arkansas was obtained (Appendix L). Surveys took about 30-45 minutes to complete. Respondents were compensated with $\$ 10$ as incentive to participate.

\section{E. Analytic Strategy}


Power Analysis. Previous research examining the effects of brief, passive psychoeducation on knowledge of intimate partner violence among a sample of Latinos living in the U.S. found a Cohen's $f^{2}$ effect size of 0.30 (Bridges et al., 2014), which represents a large effect (Cohen, 1988). For the purpose of this study, I powered more conservatively for a medium effect size of $f^{2}=0.15$. A preliminary power analysis indicated that in order to detect a medium effect of $\mathrm{f}^{2}=0.15$ at an alpha level of 0.05 and with $80 \%$ power using a regressionbased approach with three predictors and two covariates, a sample size of 77 participants was needed.

Data Screening. The data were entered in IBM SPSS 21. Descriptive statistics were obtained in order to screen the data for collinearity, outliers, and missing values. Missingness was examined by dummy coding missingness and then correlating it to sociodemographic variables, independent variables, and outcome measures (Allison, 2002; Enders, 2010). Missingness was positively associated with lower levels of education and acculturation. For participants that had more than $80 \%$ of responses for any given scale, a total score was calculated for that scale by taking the average of the items answered and multiplying this average by the number of items in the scale. For participants that answered at least 10 out of 12 questions on the literacy quiz, a percentage score was calculated based on the total number of items answered.

The data were examined to ensure compliance with the assumption of normality. A correlation of $r>.9$ or a Variance Inflation Factor (VIF) greater than 10 was used as a benchmark for multicollinearity (Myers, 1990). None of the variables were redundant; thus, all of them were included in the subsequent analyses. Outliers were considered to be data points that fell outside of three standard deviations from the mean of a scale. Only one outlier was present in the data. The data were then examined for the presence of kurtosis and skewness, using 
benchmarks of $\geq 2$ for skewness and $\geq 4$ for kurtosis respectively (Tabachnick \& Fidell, 2007). There was no significant skewness or kurtosis on any of the variables used.

Analyses. Pearson product moment correlations were completed as indices of association between continuous variables. Point-biserial correlations were completed as indices of association between continuous variables and gender. In addition, t-tests were used to examine differences between the control and experimental groups on the main variables of interest. Finally, to further explore the nature of the relationships between the variables of interest and to test my hypothesized serial mediation model, I performed a path analysis using the AMOS 18.0 statistical package (Arbuckle, 2006). Indices of goodness of data fit included chi-square (with nonsignificant $p$-value as the criterion for fit); Comparitive Fit Index (CFI) (with CFI greater than .95 as the criterion for fit); and the Root Mean Square Error of Approximation (with RMSEA less than .06 as the criterion for fit; Schumacker \& Lomax, 2012). Path analysis was performed because it allows for examination of situations in which there are hypothesized "chains" of influence and multiple dependent variables.

\section{Results}

\section{A. Descriptive Statistics}

The means and standard deviations of all of the variables of interest are shown in Table 1. Participants demonstrated a comparable level of suicide literacy to that found in previous studies (e.g., Batterham et al., 2013a; Calear, Batterham, \& Christensen, 2014). Participants reported a low level of stigma (a mean score of 11.37 suggests that the sample is "probably willing" to interact with a suicidal person). Finally, participants reported fairly positive attitudes toward seeking professional psychological help (a mean score of 11.95 across the five positively worded 
items suggests that the sample at least "partially agrees" that seeking professional psychological help for suicidality would be helpful).

Participants reported a mild level of depression overall. Using the clinical cutoff scores proposed by Lewinsohn, Seeley, Roberts, and Allen (1997), 34.6\% of the participants had scores suggestive of moderate depression, whereas the remainder fell below the clinical cutoff. Seventy percent of the sample has never experienced any suicidal ideation, $16.7 \%$ said that they had rarely thought about killing themselves in their lifetime, $6.4 \%$ said that they had sometimes thought about killing themselves in their lifetime, 3.8\% said they had often thought about killing themselves in their lifetime, and $1.3 \%$ said that they had thought about killing themselves in their lifetime very often. Furthermore, $88.5 \%$ of the sample indicated that they have never attempted suicide, while $5.1 \%$ reported one prior attempt and $5.2 \%$ reported two or more prior attempts. Of those that attempted suicide, $14 \%$ reported a low desire to die during their most recent attempt and $86 \%$ reported a high desire to die during their most recent attempt.

\section{B. Correlations Between Study Variables}

Table 1 shows the intercorrelations between the variables in the study. Most of the relationships were in the hypothesized direction. Acculturation had a significant negative association with non-stigmatizing attitudes toward suicidal behavior (as measured by the Social Distance Scale). Level of education had a significant positive association with literacy scores at time one (prior to receiving psychoeducation) and time two (immediately following psychoeducation). Depression was strongly positively associated with suicidal behavior, and exposure to suicide had a significant moderately positive relationship with literacy at time two. Non-stigmatizing attitudes toward suicidal behavior (as measured by the Social Distance Scale) was moderately associated with positive attitudes toward help seeking for suicidality. 


\section{Effects of Psychoeducation}

Independent samples t-tests were run to compare literacy scores, stigma, and attitudes toward seeking help after receiving psychoeducation in the control and experimental conditions. There was a significant difference between literacy percent correct scores for the experimental $(M=82 \%, \mathrm{SD}=13 \%)$ and control $(M=76 \%, \mathrm{SD}=12 \%)$ conditions, $t(76)=2.16, p=.03$ These results indicate participants who received brief, passive psychoeducation about suicide performed better on a suicide literacy quiz than participants who received psychoeducation about walking. There was not a significant difference between non-stigmatizing attitude scores for the experimental $(M=11.00, \mathrm{SD}=3.29)$ and control $(M=11.76, \mathrm{SD}=2.76)$ conditions, $t(74)=-$ $1.07, p=.29$. There was also not a significant difference in positive attitudes toward seeking help between the experimental $(M=12.33, \mathrm{SD}=2.42)$ and control $(M=11.56, \mathrm{SD}=2.43)$ conditions, $t(76)=1.40, p=.17$. These results suggest that brief, passive psychoeducation about suicide was not effective at changing stigmatizing attitudes toward suicidal individuals, nor was it effective at improving attitudes toward seeking professional psychological help.

\section{Path Analyses}

To test the hypothesized mechanism of change, I performed a path analysis using full information maximum likelihood estimation because the data were distributed normally (Kline, 2005). First, the full model (Model 1; Figure 4) was examined. The model included three sets of predictors of attitudes toward seeking help: psychoeducation, literacy after receiving psychoeducation, and non-stigmatizing attitudes, as well as two covariates (baseline literacy and educational attainment). Results showed that the model provided a good fit for the data, $\chi^{2}(3)=$ $0.38, p=.944, \mathrm{CFI}=1.00, \mathrm{RMSEA}=.00,90 \%$ confidence interval for $\mathrm{RMSEA}=.00-.03$. Because I had hypothesized that psychoeducation would affect help seeking attitudes through 
increased literacy and, in turn, decreased stigma, a second path model (Model 2; Figure 5) was examined that excluded direct paths from psychoeducation condition to stigma and help seeking attitudes, and from literacy to help seeking attitudes. This model also fit the data well, $\chi^{2}(6)=$ $3.69, p=.718, \mathrm{CFI}=1.00, \mathrm{RMSEA}=.00,90 \%$ confidence interval for $\mathrm{RMSEA}=.00-.11$. This trimmed model was not statistically inferior to the full model, $X^{2}$ diff $(3)=3.31, p>.05$.

In the final model, psychoeducation was significantly associated with literacy, after controlling for baseline literacy and educational attainment. Non-stigma was also strongly positively associated with positive attitudes toward seeking psychological help. However, literacy did not predict reductions in stigma, nor did it directly or indirectly predict increases in positive attitudes towards help-seeking for suicidality.

\section{Discussion}

Due to the drastic underutilization of mental health services by Latino immigrants despite rates of suicidal behaviors that are comparable to those found in the general population, research examining factors that may influence help-seeking for this population is imperative. Although previous research has shown that mental health literacy is low and mental illness, particularly suicidal behavior, is highly stigmatized among Latino immigrants, research examining the influences of suicide literacy and suicide stigma on Latinos' attitudes toward professional mental health treatment is still severely lacking. Guided by the health belief model, the current study investigated whether treatment underutilization by Latino immigrants could be partially explained by lower mental health literacy which, in turn, would be associated with higher levels of stigma. Relatedly, I also investigated whether brief, passive psychoeducation would increase suicide literacy, decrease suicide stigma, and increase positive attitudes toward treatment-seeking among Latino immigrants. 
I hypothesized the experimental group that read a brochure about suicide would demonstrate greater suicide literacy than the control group that read a brochure about walking. This hypothesis was supported. Psychoeducation in the form of a brochure was found to have a small but significant effect on literacy; participants in the experimental group scored five percentage points higher on a suicide literacy quiz than participants in the control group, controlling for level of educational attainment and baseline literacy. Of note, participants with higher educational attainment not only demonstrated greater literacy at baseline, but also were more likely to show an increase in literacy after receiving psychoeducation. This is consistent with previous findings showing psychoeducation is generally more effective for individuals who are already knowledgeable and agree with its message (Devine, 1995).

I also hypothesized the experimental group would demonstrate lower levels of stigma and more positive attitudes toward seeking help than the control group. These hypotheses were not substantiated. Although brief, passive psychoeducation increased literacy rates, it did not directly or indirectly (through literacy) decrease stigmatizing attitudes towards suicidality nor did it impact positive help-seeking attitudes. As such, the serial mediation model I hypothesized did not hold up. However, lower stigma was related to more positive attitudes toward help-seeking, consistent with previous findings (e.g., Barney et al., 2006; Corrigan, 2004; Link \& Phelan, 2006).

Corrigan and Penn (1999) have identified three approaches for reducing stigma: protest, education, and contact. Previous research (Penn \& Corrigan, 2002) has shown that the first approach, which involves telling people to stop having negative opinions toward individuals with mental illness, has a limited effect on reducing stigma. Specifically, Penn and Corrigan (2002) found that instruction to suppress stereotypes did reduce stigmatizing attitudes, but did not 
change behavior toward people with mental illness. It has also been suggested that stereotype suppression could have a rebound effect, in which participants are actually primed to have more negative attitudes toward a stigmatized group as a result of the intervention (e.g., Macrae, Bodenhausen, Milne, \& Jetten, 1994). Thus, findings regarding the effectiveness of protest as a stigma reduction technique are mixed.

I examined the second of these three approaches in my study, finding that increasing knowledge through brief, passive psychoeducation was insufficient to produce attitude change. There are a number of possible explanations for my failure to find this effect. First, Penn, Kommana, Mansfield, and Link (1999) found that, when attempting to dispel stigma about schizophrenia, providing information about the relationship between dangerousness and schizophrenia was especially important in creating attitude change. Thus, it could be that my psychoeducational materials did not go far enough in explicitly speaking to the danger (or lack thereof) that suicidal individuals pose toward other people. Penn and colleagues (1999) also found the positive effects of education on stigma were attenuated when participants had to rate their experiences with an actual individual with serious mental illness. This could also explain my inability to find a relationship between literacy and stigma, because I measured stigma with regard to a specific hypothetical individual, rather than stigma toward suicidal people in general. It may also be that brief, passive psychoeducation provides an insufficient dose of education to result in measurable attitude change.

The final suggested approach to reducing stigma is increased contact with individuals with mental illness. Specifically, reductions in stigma as a result of direct contact are greatest when the interpersonal interaction is defined by shared goals and equal status, and is supported by people in positions of power (Corrigan \& Penn, 1999; Pettigrew \& Tropp, 2006). Evidence 
suggests that this approach may have the most substantial impact on attitudinal change (Corrigan et al., 2001), and has been linked to behavioral change as well (Corrigan et al., 2003a, 2003b). Of note, greater exposure to suicidal people was associated with lower levels of stigma in the current study; however, this association was not significant. Unfortunately, very little work has examined how direct interpersonal contact affects stigma during ongoing, naturalistic relationships. One hypothesized mechanism of change for this final stigma reduction approach is that direct interpersonal contact helps people to recognize that individuals with mental illness are not responsible for their condition (Corrigan, 2000). Thus, psychoeducational materials could be improved by including an explicit discussion of the uncontrollability of mental illness (and, in this case, suicidal behavior).

Surely, the most effective means of combating stigma toward suicidal individuals would involve a combination of these three approaches. Protest and stereotype suppression can be helpful with regard to reducing negative attitudes toward suicidal individuals, but education is necessary for fostering more positive attitudes that are well-informed and based in fact. Unfortunately, it seems that brief, passive psychoeducation in the form of a brochure may not be effective at reducing stigma toward suicidal individuals. In the future, research should examine the effects of more active forms of psychoeducation that involve both teaching and discussion about suicidal individuals. Indeed, prior research has found participants are more likely to reject false assumptions and remember accurate information when they are able to discuss the material with teachers and peers (Lynch, 1987; Quicke, Beasley, \& Morrison, 1990). Psychoeducation efforts may also benefit from a focus on explicitly disconfirming false beliefs individuals may have about suicidal people. Finally, education strategies may be augmented by direct interpersonal contact with suicidal individuals, as it has been shown that direct interpersonal 
contact with a person with mental illness is the most effective way of diminishing psychiatric stigma (Couture \& Penn, 2003).

Although improving mental health literacy did not directly improve attitudes toward seeking professional psychological help, lower stigma toward suicidal individuals was associated with more positive attitudes toward seeking help for emotional problems. In fact, concern about the stigma associated with being identified as having a mental illness is one of the most commonly cited barriers to seeking help (Gulliver, Griffiths, \& Christensen, 2010; Jorm, Wright, \& Morgan, 2007; Pescosolido et al., 2010). Thus, stigma reduction efforts should, theoretically, improve help-seeking attitudes. Indeed, numerous studies in the extant literature support the claim that stigma reduction efforts are also effective at improving help-seeking attitudes (e.g., Rickwood, Cavanagh, Curtis, \& Sakrouge, 2004; Saporito, Ryan, \& Teachman, 2011). In general, it seems that efforts to improve attitudes toward seeking professional psychological help for emotional problems may use a combined approach that includes education and greater contact with service providers in the community.

\section{A. Limitations and Future Directions}

The results of this study should be considered in light of its limitations. First, my findings are based entirely on self-report data. This is problematic because responses to attitudinal and stigma measures are especially likely to be influenced by social desirability effects. In addition, the difference between expressed stigma and actual discriminatory behavior should be considered, because shifts in self-reported attitudes can occur without any change in behavior (Devine, 1989). Incorporating implicit and behavioral measures of stigma could be a useful strategy for addressing both of these limitations (Corrigan \& Shapiro, 2010). In a similar vein, although attitudes toward treatment-seeking have been shown to be an important predictor 
of intentions and future behavior (Ajzen \& Fishbein, 1980), determining whether self-reported stigma and attitudes toward treatment-seeking are predictors of actual help-seeking behavior is an important next step. Another weakness of my study was that the assessment of stigma was limited to participants' responses to a single example in a hypothetical vignette. In addition, literacy showed only a modest increase following psychoeducation in my study. As such, it would be worthwhile to examine the effects of literacy on stigma and treatment-seeking attitudes in other psychoeducation conditions that may be able to produce a greater change in literacy. Finally, the sample size for this study was fairly small, and I collected my data from participants with a relatively unique demographic composition. As such, this study should be replicated among other ethnic and age groups to extend the generalizability of my findings.

\section{B. Conclusions}

Low mental health literacy and stigma surrounding mental illness have been identified as barriers that may prevent help-seeking among Latino immigrants. A common intervention technique for targeting mental health literacy and stigma is the provision of psychoeducational brochures, because they are much easier and less expensive to provide than active psychoeducation and treatment. Although brief, passive psychoeducation in the form of a brochure was found to be effective at increasing suicide literacy in this population, it was not sufficient to produce attitudinal change toward suicidal individuals or help-seeking. As such, future efforts to reduce stigma and increase help-seeking among this population should involve more active forms of psychoeducation that focus explicitly on disconfirming false beliefs about suicidal individuals, as well as direct interpersonal contact with suicidal individuals. 


\section{References}

Ahmedani, B. K., Perron, B., Ilgen, M., Abdon, A., Vaughn, M., \& Epperson, M. (2012). Suicide thoughts and attempts and psychiatric treatment utilization: Informing prevention strategies. Psychiatric Services, 63, 186-189. doi:10.1176/appi.ps.201100159

Ajzen, I., \& Fishbein, M. (1980). Understanding attitudes and predicting social behavior. Englewood Cliffs, NH: Prentice Hall.

Alegría, M., Chatterji, P., Wells, K., Cao, Z., Chen, C. N., Takeuchi, D., .. Meng, X. L. (2008). Disparity in depression treatment among racial and ethnic minority populations in the United States. Psychiatric Services, 59, 1264-1272. doi:10.1176/appi.ps.59.11.1264

Allison, P. (2002). Missing data. Thousand Oaks, CA: Sage.

Alvidrez, J. (1999). Ethnic variations in mental health attitudes and service use among lowincome African American, Latina, and European American young women. Community Mental Health Journal, 35, 515-530. doi:10.1023/A:1018759201290

American Psychiatric Association. (2013). Diagnostic and statistical manual of mental disorders ( $5^{\text {th }}$ ed.). Arlington, VA: American Psychiatric Publishing.

American Psychological Association, Task Force on Immigration. (2012). Crossroads: The psychology of immigration in the New Century. Report of the APA Presidential Task Force on Immigration. Retrieved from http://www.apa.org/topics/immigration/immigration-report.pdf

Arbuckle, J. L. (2006). Amos (Version 7.0) [Computer Program]. Chicago: SPSS.

Barney, L. J., Griffiths, K. M., Jorm, A. F., \& Christensen, H. (2006). Stigma about depression and its impact on help-seeking intentions. Australian and New Zealand Journal of Psychiatry, 40, 51-54. doi:10.1111/j.1440-1614.2006.01741.x

Batterham, P. J., Calear, A. L., \& Christensen, H. (2013a). Correlates of suicide stigma and suicide literacy in the community. Suicide and Life-Threatening Behavior, 43, 406-417. doi:10.1111/sltb.12026

Batterham, P. J., Calear, A. L., \& Christensen, H. (2013b). The stigma of suicide scale: Psychometric properties and correlates of the stigma of suicide. Crisis, 34, 13-21. doi:10.1027/0227-5910/a000156

Bertolote, J. M., \& Fleischmann, A. (2002). Suicide and psychiatric diagnosis: A worldwide perspective. World Psychiatry, 1, 181-185. Retrieved from http://www.ncbi.nlm.nih.gov/pmc/articles/PMC1489848/

Borges, G., Orozco, R., Rafful, C., Miller, E., \& Breslau, J. (2012). Suicidality, ethnicity and 
immigration in the USA. Psychological medicine, 42, 1175-1184. doi:10.1017/S0033291711002340

Bridges, A. J., Andrews, A. R., \& Deen, T. L. (2012). Mental health needs and service utilization by Hispanic immigrants residing in mid-Southern United States. Journal of Transcultural Nursing, 23(4), 359-368. doi:10.1177/1043659612451259

Bridges, A. J., Karlsson, M., \& Lindly, E. (2014). The effect of brief, passive psychoeducation on knowledge and ratings of intimate partner violence in the United States and Argentina. Journal of Interpersonal Violence, 29, 1-23. doi:10.1177/0886260514534775

Brislin, R. W. (1970). Back-translation for cross-cultural research. Journal of CrossCultural Psychology, 1(3), 185-216. doi:10.1177/135910457000100301

Burnham, M. A., Hough, R. L., Karno, M., Escobar, J. I., \& Telles, C. A. (1987). Acculturation and lifetime prevalence of psychiatric disorders among Mexican Americans in Los Angeles. Journal of Health and Social Behavior, 28, 89-102. doi:10.2307/2137143

Cabassa, L. (2007). Latino immigrant men's perceptions of depression and attitudes toward help seeking. Hispanic Journal of Behavioral Sciences, 29, 492-509. doi:10.1177/0739986307307157

Cabassa, L. J., \& Zayas, L. H. (2007). Latino immigrants' intentions to seek depression care. American Journal of Orthopsychiatry, 77, 231-242. doi:10.1037/0002-9432.77.2.231

Calear, A. L., Batterham, P. J., \& Christensen, H. (2012). The literacy of suicide scale: Psychometric properties and correlates of suicide literacy. Unpublished manuscript.

Calear, A. L., Batterham, P. J., \& Christensen, H. (2014). Predictors of help-seeking for suicidal ideation in the community: Risks and opportunities for public suicide prevention campaigns. Psychiatry Research, 219, 525-530. doi:10.1016/j.psychres.2014.06.027

Center for Disease Control and Prevention. (2012). Ten leading causes of death, United States. Retrieved from http://www.cdc.gov/injury/wisqars/index.html

Cohen, J. E. (1988). Statistical power analysis for the behavioral sciences. Hillsdale, NJ: Lawrence Erlbaum Associates, Inc.

Corrigan, P. W. (2000). Mental health stigma as social attribution: Implications for research methods and attitude change. Clinical Psychology: Science and Practice, 7, 48-67. doi:10.1093/clipsy.7.1.48

Corrigan, P. W. (2004). How stigma interferes with mental health care. American Psychologist, 59, 614-625. doi:10.1037/0003-066X.59.7.614

Corrigan, P. W., \& Penn, D. L. (1999). Lessons from social psychology on discrediting 
psychiatric stigma. American Psychologist, 54, 765-776.

doi:10.1037/0003-066X.54.9.765

Corrigan, P. W., \& Shapiro, J. R. (2010). Measuring the impact of programs that challenge the public stigma of mental illness. Clinical Psychology Review, 30, 907-922. doi:10.1016/j.cpr.2010.06.004

Corrigan, P. W., River, L. P., Lundin, R. K., Penn, D. L., Uphoff-Wasowski, K., Campion, J., ...Kubiak, M. A. (2001). Three strategies for changing attributions about severe mental illness. Schizophrenia Bulletin, 27, 187-195. doi:10.1093/oxfordjournals.schbul.a006865

Corrigan, P. W., Markowitz, F. E., Watson, A., Rowan, D., \& Kubiak, M. A. (2003a). An attribution model of public discrimination towards persons with mental illness. Journal of Health and Social Behavior, 44, 162-179. doi:10.2307/1519806

Corrigan, P. W., Thompson, V., Lambert, D., Sangster, Y., Noel, J., \& Campbell, J. (2003b). Perceptions of discrimination among persons with serious mental illness. Psychiatric Services, 54, 1105-1110. doi:10.1176/appi.ps.54.8.1105

Couture, S. M., \& Penn, D. L. (2003). Interpersonal contact and the stigma of mental illness: A review of the literature. Journal of Mental Health, 12, 291-305. doi:10.1080/09638231000118276

De Leo, D., Burgis, S., Bertolote, J. M., Kerkhof, A. J., \& Bille-Brahe, U. (2006). Definitions of suicidal behavior: Lessons learned from the WHO/EURO multicentre study. Crisis, 27, 4-15. doi:10.1027/0227-5910.27.1.4

Deen, T. L., \& Bridges, A. J. (2011). Depression literacy: rates and relation to perceived need and mental health service utilization in a rural American sample. Rural and Remote Health, 11, 1-13. doi:10.1007/s00127-009-0031-7

Devine, P. G. (1989). Stereotypes and prejudice: Their automatic and controlled components. Journal of Personality and Social psychology, 56, 5-18. doi:10.1037/0022-3514.56.1.5

Devine, P. G. (1995). Prejudice and out-group perception. In A. Tesser (Ed.), Advanced social psychology (pp. 467-524). New York: McGraw-Hill.

Donker, T., Griffiths, K. M., Cuijpers, P., \& Christensen, H. (2009). Psychoeducation for depression, anxiety and psychological distress: A meta-analysis. BMC Medicine, 7, 1-9. doi:10.1186/1741-7015-7-79

Dwight-Johnson, M., Lagomasino, I. T., Hay, J., Zhang, L., Tang, L., Green, J. M., \& Duan, N. (2010). Effectiveness of collaborative care in addressing depression treatment preferences among low-income Latinos. Psychiatric Services, 61, 1112-1118. doi:10.1176/appi.ps.61.11.1112 
Elhai, J. D., Schweinle, W., \& Anderson, S. M. (2008). Reliability and validity of the Attitudes Toward Seeking Professional Psychological Help Scale - Short Form. Psychiatry Research, 159, 320-329. doi:10.1016/j.psychres.2007.04.020

Enders, C. K. (2010). Applied missing data analysis. New York, NY: Guilford Publications.

Falcon, L. M., \& Tucker, K. L. (2000). Prevalence and correlates of depressive symptoms among Hispanic elders in Massachusetts. Journal of Gerontology, 55, S108 - S116. doi:10.1093/geronb/55.2.S108

Finch, B. K., Hummer, R. A., Kolody, B., \& Vega, W. A. (2001). The role of discrimination and acculturative stress in the physical health of Mexican-origin adults. Hispanic Journal of Behavioral Sciences, 23, 399-429. doi:10.1177/0739986301234004

Fischer, E. H., \& Farina, A. (1995). Attitudes toward seeking professional psychological help: A shortened form and considerations for research. Journal of College Student Development, 36, 368-373. doi:10.1037/t05375-000

Griffiths, K. M., Christensen, H., Jorm, A. F., Evans, K., \& Groves, C. (2004). Effect of webbased depression literacy and cognitive-behavioural therapy interventions on stigmatizing attitudes to depression. British Journal of Psychiatry, 185, 342-349.

doi:10.1192/bjp.185.4.342

Guarnaccia, P. J., Martinez, I., \& Acosta, H. (2005). Mental health in the Hispanic immigrant community: An overview. Journal of Immigrant and Refugee Services, 3, 21-46. doi:10.1300/J191v3n01_02

Gulliver, A., Griffiths, K. M., \& Christensen, H. (2010). Perceived barriers and facilitators to mental health help-seeking in young people: A systematic review. BMC Psychiatry, 10, 1-9. doi:10.1186/1471-244X-10-113

Gvion, Y., \& Apter, A. (2012). Suicide and suicidal behavior. Public Health Reviews, 34, 1-20. Retrieved from http://www.publichealthreviews.eu/upload/pdf_files/12/00_Gvion.pdf

Hough, R. L., Landsverk, J. A., Karno, M., Burnam, M. A., Timbers, D. M., Escober, J. I., \& Regier, D. A. (1987). Utilization of health and mental health services by Los Angeles Mexican Americans and non-Hispanic Whites. Archives of General Psychiatry, 44, 702709. doi:10.1001/archpsyc.1987.01800200028005

Hovey, J. D. (1999). Religion and suicidal ideation in a sample of Latin American immigrants. Psychological Reports, 85, 171-177. doi:10.2466/PR0.85.5.171-177

Interian, A., Ang, A., Gara, M.A., Link, B.G., Rodriguez, M.A., \& Vega, W.A. (2010). Stigma and depression treatment utilization among Latinos: Utility of four stigma measures. Psychiatric Services, 61(4), 373-379. doi:10.1176/appi.ps.61.4.373 
Jorm, A. F. (2000). Mental health literacy: Public knowledge and beliefs about mental disorders. British Journal of Psychiatry, 177, 396-401. doi:10.1192/bjp.177.5.396

Jorm, A. F., Wright, A., \& Morgan, A. J. (2007). Where to seek help for a mental disorder? National survey of the beliefs of Australian youth and their parents. The Medical Journal of Australia, 187, 556-560.

Jorm, A. F., Griffiths, K. M., Christensen, H., Korten, A. E., Parslow, R. A., \& Rodgers, B. (2003). Providing information about the effectiveness of treatment options to depressed people in the community: A randomized controlled trial of effects on mental health literacy, help-seeking and symptoms. Psychological Medicine, 33, 1071-1079. doi:10.1017/S0033291703008079

Kline, R. B. (2005). Principles and practice of structural equation modeling. New York, NY: Guilford Press.

Kouyoumdijian, H., Zamoanga, B. L., \& Hansen, D. J. (2003). Barriers to community mental health services for Latinos: Treatment considerations. Clinical Psychology: Science and Practice, 10, 394-422. doi:10.1093/clipsy/bpg041

Larkin, G. L., Rivera, H., Xu, H., Rincon, E., \& Beautrais, A. L. (2011). Community responses to a suicidal crisis: Implications for suicide prevention. Suicide \& Life-Threatening Behavior, 41, 79-86. doi:10.1111/j.1943-278X.2010.00013.x

Lewinsohn, P. M., Seeley, J. R., Roberts, R. E., \& Allen, N. B. (1997). Center for Epidemiological Studies-Depression Scale (CES-D) as a screening instrument for depression among community-residing older adults. Psychology and Aging, 12, 277- 287. doi:10.1037/0882-7974.12.2.277

Link, B. G., \& Phelan, J. C. (2006). Stigma and its public health implications. Lancet, 367, 528529. doi:10.1016/S0140-6736(06)68184-1

Link, B. G., Phelan, J. C., Bresnahan, M., Stueve, A., \& Pescosolido, B. A. (1999). Public conceptions of mental illness: Labels, causes, dangerousness, and social distance. American Journal of Public Health, 89, 1328-1333. doi:10.2105/ajph.89.9.1328

Link, B. G., Yang, L. H., Phelan, J. C., \& Collins, P. Y. (2004). Measuring mental illness stigma. Schizophrenia Bulletin, 30, 511-541. doi:10.1093/oxfordjournals.schbul.a007098

Lukens, E. P., \& McFarlane, W. R. (2004). Psychoeducation as evidence-based practice: Considerations for practice, research, and policy. Brief Treatment and Crisis Intervention, 4, 205-225. doi:10.1093/brief-treatment/mhh019

Luoma, J. B., Martin, C. E., \& Pearson, J. L. (2002). Contact with mental health and primary care providers before suicide: A review of the evidence. American Journal of Psychiatry, 159, 909-916. doi:10.1176/appi.ajp.159.6.909 
Lynch, J. (1987). Prejudice reduction and the schools. London: Cassell.

Macrae, C. N., Bodenhausen, G. V., Milne, A. B., \& Jetten, J. (1994). Out of mind but back in sight: Stereotypes on the rebound. Journal of Personality and Social Psychology, 67, 808-817. doi:10.1037/0022-3514.67.5.808

Mann, J. J. (2003). Neurobiology of suicidal behaviour. Nature Reviews Neuroscience, 4, 819828. doi:10.1038/nrn1220

Marquez, J., \& Ramirez García, J. (2013). Family caregivers' narratives of mental health treatment usage processes by their Latino adult relatives with serious and persistent mental illness. Journal of Family Psychology, 27, 398-408. doi:10.1037/a0032868

Migration Policy Institute. (2011). ELL information center. Retrieved from http://www.migrationinformation.org/DataHub/historicaltrends.cfm

Myers, R. H. (1990). Classical and modern regression application. Duxbury press.

Nadeem, E., Lange, J. M., Edge, D., Fongwa, M., Belin, T., \& Miranda, J. (2007). Does stigma keep poor young immigrant and U.S.-born Black and Latina women from seeking mental health care? Psychiatric Services, 58, 1547-1554. doi:10.1176/appi.ps.58.12.1547

National Action Alliance for Suicide Prevention. (2014). A prioritized research agenda for suicide prevention: An action plan to save lives. Retrieved from http://actionallianceforsuicideprevention.org/sites/actionallianceforsuicideprevention.org/ files/Agenda.pdf

National Council of La Raza. (2005). Critical disparities in Latino mental health: Transforming research into action. Retrieved from http://www.nclr.org/images/uploads/publications/34798_file_WP_LatiMentHlth_ExecSu m_FNL.pdf

O’Carroll, P. W., Berman, A. L., Maris, R. W., Moscicki, E. K., Tanney, B. L., \& Silverman, M. M. (1996). Beyond the tower of Babel: A nomenclature for suicidology. Suicide and Life Threatening Behavior, 37, 248-263. doi:10.1111/j.1943-278X.1996.tb00609.x

O’Connor, E., Gaynes, B., Burda, B. U., Williams, C., \& Whitlock, E. P. (2013). Screening for suicide risk in primary care: A systematic evidence review for the U.S. preventive services task force [Internet]. Retrieved from http://www.ncbi.nlm.nih.gov/books/NBK137739/

Oquendo, M. A., Baca-García, E., Mann, J. J., \& Giner, J. (2008). Issues for DSM-V: Suicidal behavior as a separate diagnosis on a separate axis. American Journal of Psychiatry, 165, 1383-1384. doi:10.1176/appi.ajp.2008.08020281

Penn, D. L., \& Corrigan, P. W. (2002). The effects of stereotype suppression on psychiatric 
stigma. Schizophrenia Research, 55, 269-276. doi:10.1016/S0920-9964(01)00207-9

Penn, D. L., Kommana, S., Mansfield, M., \& Link, B. G. (1999). Dispelling the stigma of schizophrenia: The impact of information on dangerousness. Schizophrenia Bulletin, 25, 437-446. doi:10.1093/oxfordjournals.schbul.a033391

Pérez, D. J., Fortuna, L., \& Alegría, M. (2008). Prevalence and correlates of everyday discrimination among U.S. Latinos. Journal of Community Psychology, 36, 421-433. doi:10.1002/jcop.20221

Perez-Rodriguez, M., Baca-Garcia, E., Oquendo, M. A., Wang, S., Wall, M. M., Liu, S., \& Blanco, C. (2014). Relationship between acculturation, discrimination, and suicidal ideation and attempts among U.S. Hispanics in the National Epidemiologic Survey of Alcohol and Related Conditions. Journal of Clinical Psychiatry, 75, 399-407. doi: $10.4088 / \mathrm{JCP} .13 \mathrm{~m} 08548$

Pescosolido, B. A., Martin, J. K., Long, J. S., Medina, T. R., Phelan, J. C., \& Link, B. G. (2010). "A disease like any other?" A decade of change in public reactions to schizophrenia, depression, and alcohol dependence. American Journal of Psychiatry, 167, 1321-1330. doi:10.1176/appi.ajp.2010.09121743

Pettigrew, T. F., \& Tropp, L. R. (2006). A meta-analytic test of intergroup contact theory. Journal of Personality and Social Psychology 90, 751-783.

doi:10.1037/0022-3514.90.5.751

Quicke, J., Beasley, K., \& Morrison, C. (1990). Challenging prejudice through education: The story of a mental handicap awareness curriculum project. Bristol, PA: Falmer Press.

Rickwood, D., Cavanagh, S., Curtis, L., \& Sakrouge, R. (2004). Educating young people about mental health and mental illness: Evaluating a school-based programme. International Journal of Mental Health Promotion, 6, 23-32. doi:10.1080/14623730.2004.9721941

Rojas-Vilches, A. P., Negy, C., \& Reig-Ferrer, A. (2011). Attitudes toward seeking therapy among Puerto Rican and Cuban American young adults and their parents. International Journal of Clinical and Health Psychology, 11, 313-341. Retrieved from http://dps.ua.es/es/documentos/pdf/2011/attitudes-toward-seeking-therapy-among-puertorican-and-cuban-american-young-adults-and-their-pare.pdf

Rosenstock, I. M., Strecher, V. J., \& Becker, M. H. (1988). Social learning theory and the Health Belief Model. Health Education Quarterly, 15, 175-183. doi:10.1177/109019818801500203

Santiago-Rivera, A. L., Kanter, J. W., Busch, A. M., Rusch, L. C., Reyes, W., West, P., \& Runge, M. (2010). Latino immigrants with depression: An initial examination of treatment issues at a community clinic. Journal of Immigrant and Minority Health, 13, 772-779. doi:10.1007/s10903-010-9380-2 
Saporito, J. M., Ryan, C., \& Teachman, B. A. (2011). Reducing stigma toward seeking mental health treatment among adolescents. Stigma Research and Action, 1, 9-21.

Schumacker, R., \& Lomax, R. (2012). A beginner's guide to structural equation modeling. Mahwah: Routledge Academic.

Sorenson, S. B., \& Golding, J. M. (1988). Prevalence of suicide attempts in a Mexican-American population: Prevention implications of immigration and cultural issues. Suicide and LifeThreatening Behavior, 18, 322-333. doi: 10.1111/j.1943-278X.1988.tb00170.x

Sue, S., Fujino, D. C., Hu, L., Takeuchi, D. T., \& Zane, N. W. S. (1991). Community mental health services for ethnic minority groups: a test of the cultural responsiveness hypothesis. Journal of Consulting and Clinical Psychology, 59, 533-540. doi:10.1037/0022-006X.59.4.533

Suicide Prevention Resource Center. (2013). Suicide among racial / ethnic populations in the U.S.: Hispanics. Waltham, MA: Education Development Center, Inc. Retrieved from http://www.sprc.org/sites/sprc.org/files/library/Hispanics\%20Sheet\%20Aug\%2028\%202 013\%20Final.pdf

Tabachnick, B. G.\& Fidell, L. S. (2007). Using multivariate statistics (5th ed.). Boston, Massachusetts: Allyn and Bacon.

Tadros, G., \& Jolley, D. (2001). The stigma of suicide. The British Journal of Psychiatry, 179, 178. doi:10.1192/bjp.179.2.178

U.S. Census Bureau. (2010). Projections of the population by race and Hispanic origin for the United States: 2008 to 2050 . Retrieved from http://www.census.gov/population/www/projections/tablesandcharts.html

U.S. Department of Health and Human Services, National Institutes of Health, National Institute of Mental Health. (2010). Suicide in America: Frequently asked questions (NIH Publication No. TR 11-7697) Retrieved from http://www.nimh.nih.gov/health/ publications/suicide-in-america/suicide-america-trifold.pdf

U.S. Department of Health and Human Services, National Institutes of Health, Weight-Control Information Network. (2014). Walking: A step in the right direction (NIH Publication No. 07-4155) Retrieved from http://win.niddk.nih.gov/publications/walking.htm

Vega, W. A., Kolody, B., Aguilar-Gaxiola, S., Alderete, E., Catalano, R., \& Caraveo-Anduaga, J. (1998). Lifetime prevalence of DSM-III-R psychiatric disorders among urban and rural Mexican Americans in California. Archives of General Psychiatry, 55, 771-778. doi:10.1001/archpsyc.55.9.771

Vega, W. A., Kolody, B., Aguilar-Gaxiola, S., \& Catalano, R. (1999). Gaps in service utilization by Mexican Americans with mental health problems. American Journal of Psychiatry 
156, 928- 934. Retrieved from

http://psychiatryonline.org/data/Journals/AJP/3701/928.pdf

Vega, W. A., Rodriguez, M. A., \& Ang, A. (2010). Addressing stigma of depression in Latino primary care patients. General Hospital Psychiatry, 32, 182-191. doi:0.1016/j.genhosppsych.2009.10.008

Wadsworth, T., \& Kubrin, C. E. (2007). Hispanic suicide in U.S. metropolitan areas: Examining the effects of immigration, assimilation, affluence, and disadvantage. American Journal of Sociology, 112, 1848-1885. doi:10.1086/512711 


\section{Table 1}

Table 1

Means, standard deviations, and correlations among measures

\begin{tabular}{|c|c|c|c|c|c|c|c|c|c|c|c|c|c|c|}
\hline Variable & 1 & 2 & 3 & 4 & 5 & 6 & 7 & 8 & 9 & 10 & 11 & 12 & Mean & $\mathrm{SD}$ \\
\hline 1. Gender & -- & & & & & & & & & & & & 0.71 & 0.46 \\
\hline 2. Age & .04 & -- & & & & & & & & & & & 36.23 & 9.95 \\
\hline 3. Acculturation & -.14 & -.16 & -- & & & & & & & & & & 10.18 & 4.70 \\
\hline 4. Education & .11 & $-.25 *$ & $.33 * *$ & -- & & & & & & & & & 4.96 & 1.63 \\
\hline 5. Depression & .12 & .03 & .03 & -.12 & -- & & & & & & & & 13.84 & 8.76 \\
\hline 6. Suicidal behavior & .19 & $-.26 *$ & .09 & .21 & $.30 *$ & -- & & & & & & & 0.96 & 2.13 \\
\hline 7. Exposure to suicide & .15 & $-.38 * *$ & .04 & .09 & .11 & $.54 * *$ & -- & & & & & & 3.78 & 3.16 \\
\hline 8. Literacy at $\mathrm{T} 1$ & .07 & -.19 & .17 & $.26^{*}$ & -.03 & .08 & .17 & -- & & & & & 0.62 & 0.16 \\
\hline 9. Literacy at $\mathrm{T} 2$ & $.25^{*}$ & -.16 & .20 & $.32 * *$ & .22 & $.26^{*}$ & .14 & $.39 * *$ & -- & & & & 0.79 & 0.13 \\
\hline 10. Stigma - SD & .03 & .08 & $-.25^{*}$ & -.21 & -.17 & -.06 & .10 & -.06 & -.15 & -- & & & 11.37 & 3.05 \\
\hline 11. Stigma - SOSS & .01 & -.10 & -.16 & -.17 & .00 & -.02 & -.09 & -.21 & -.11 & $-.24 *$ & -- & & 19.41 & 6.06 \\
\hline 12. Help seeking attitudes & .15 & -.19 & -.07 & .07 & -.22 & .03 & .17 & .12 & .13 & $.23 *$ & .01 & -- & 11.95 & 2.44 \\
\hline
\end{tabular}

Note. For gender, men were coded as "0". For "Stigma - SD", higher scores represent more acceptance.

$* p<.05, * * p<.01$ 


\section{Figures}

\section{A. Figure 1}

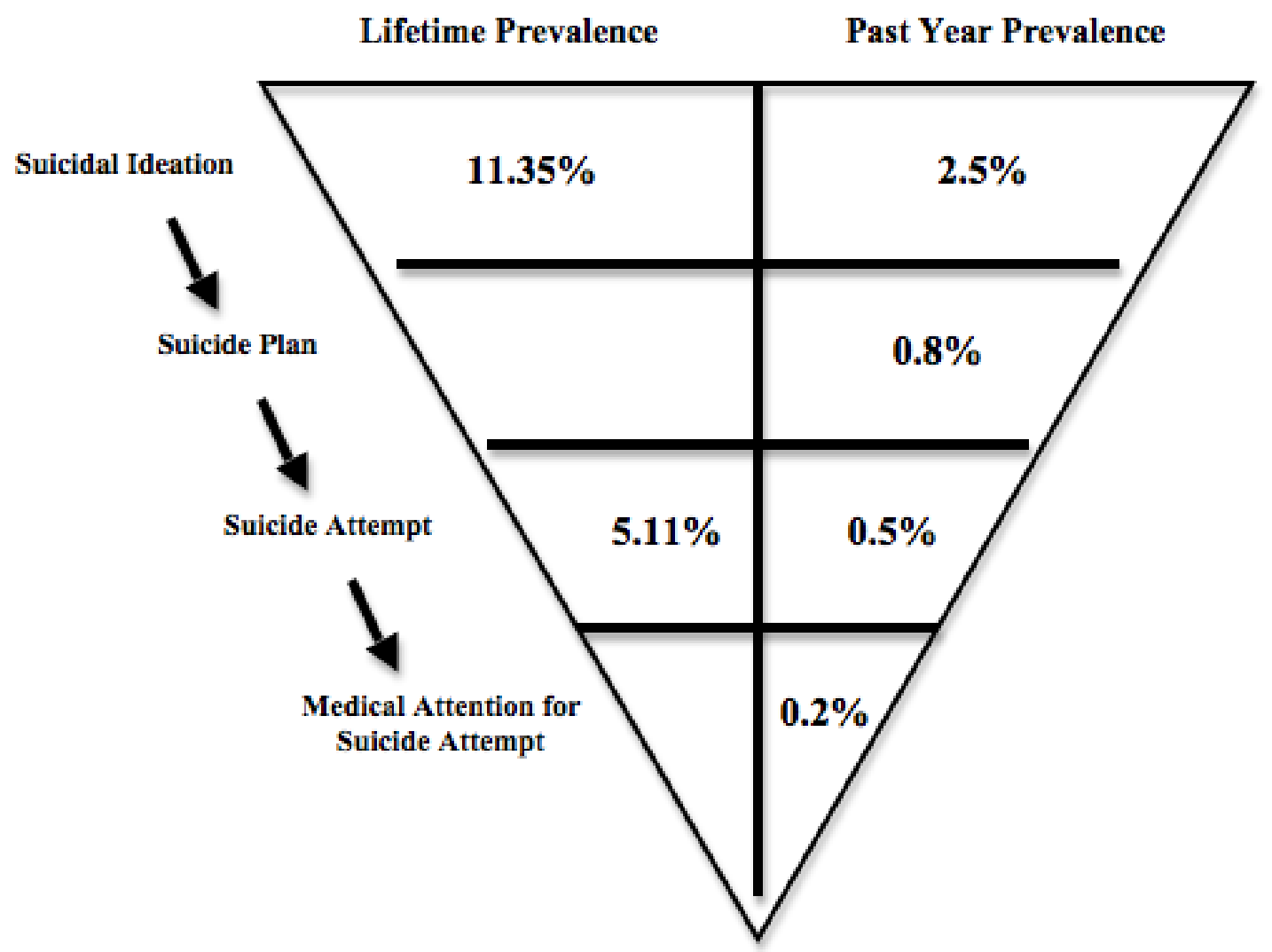

Figure 1. Twelve-month prevalence rates of suicide behaviors among Latinos. The prevalence of various suicidal behaviors exhibits a funnel-like shape, with completed suicide being at the narrowest point of the funnel, and suicidal ideation being at the widest point (Suicide Prevention Resource Center, 2013). 


\section{B. Figure 2}

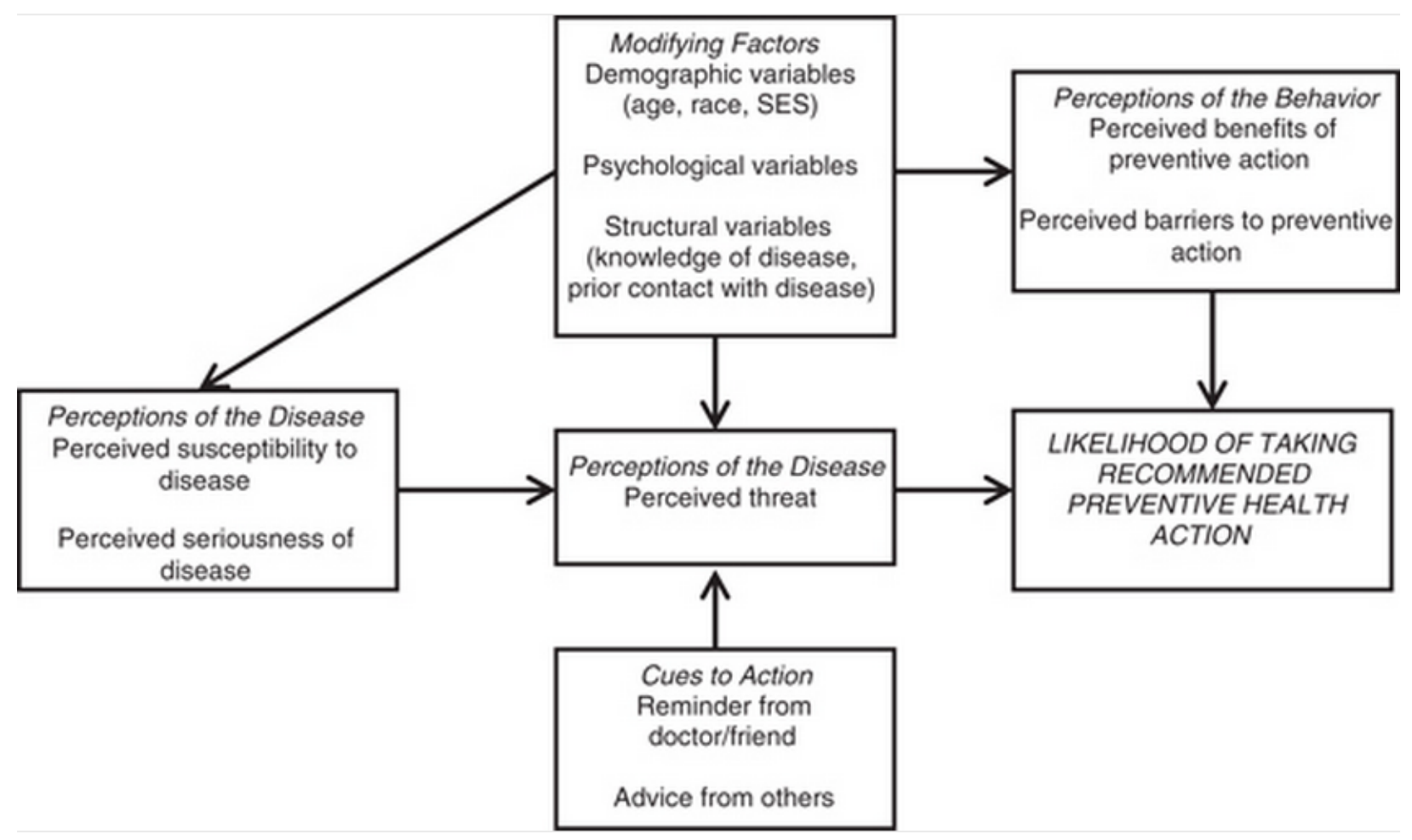

Figure 2. The health belief model. 
C. Figure 3

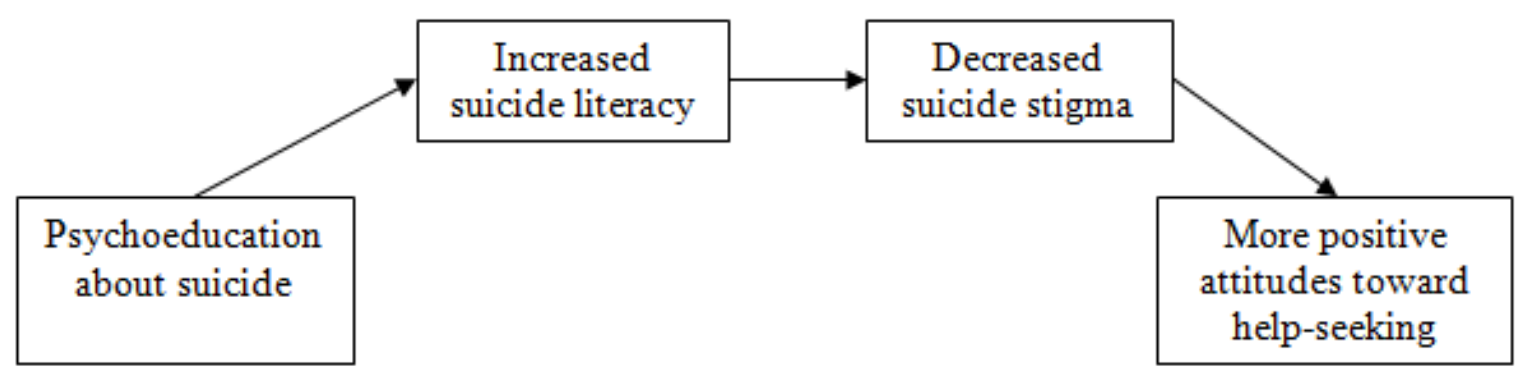

Figure 3. Hypothesized mediated mechanism of change. 
D. Figure 4

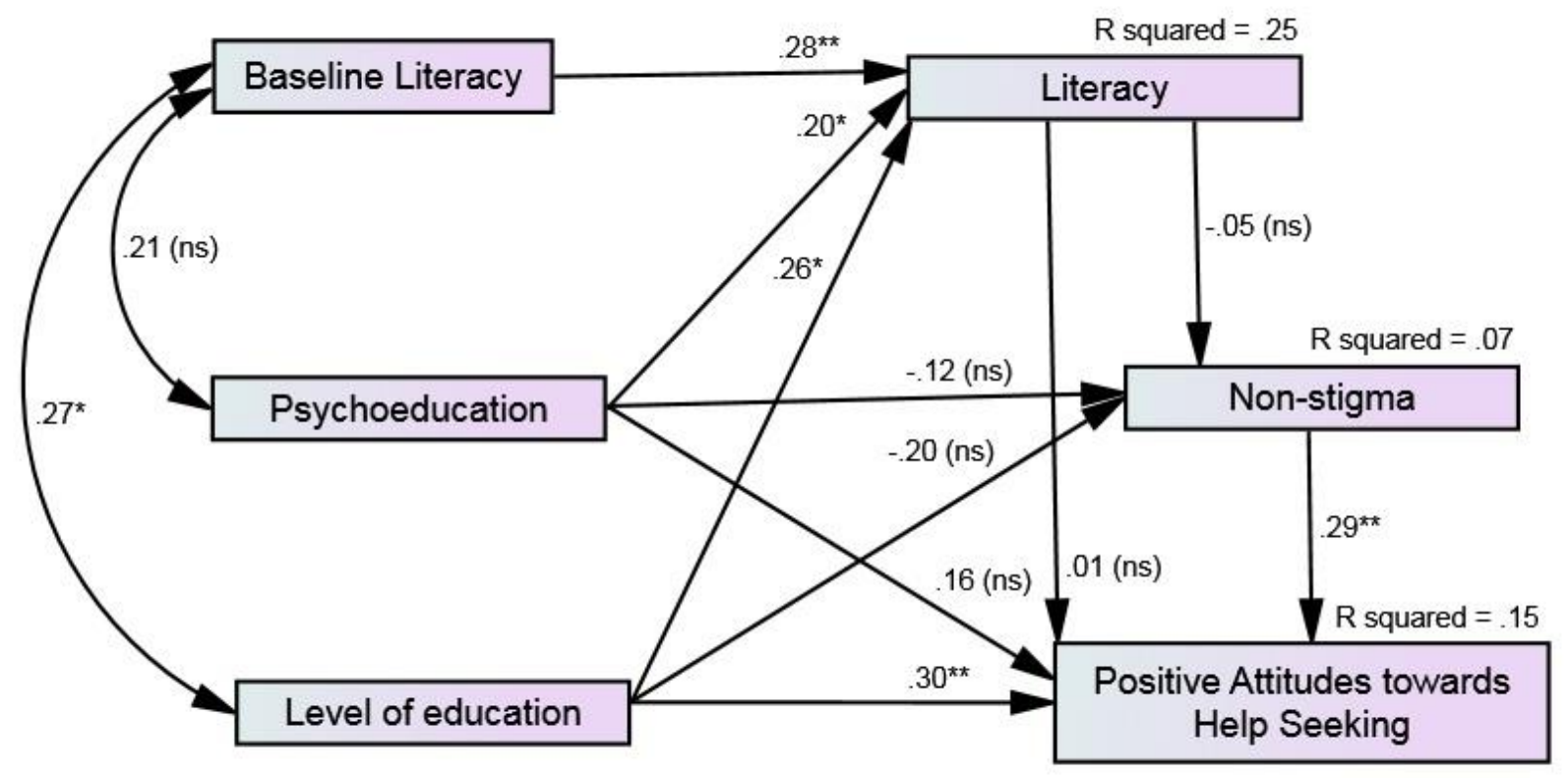

Figure 4. Full hypothesized model. $* p<.05, * * p<.01$ 


\section{E. Figure 5}

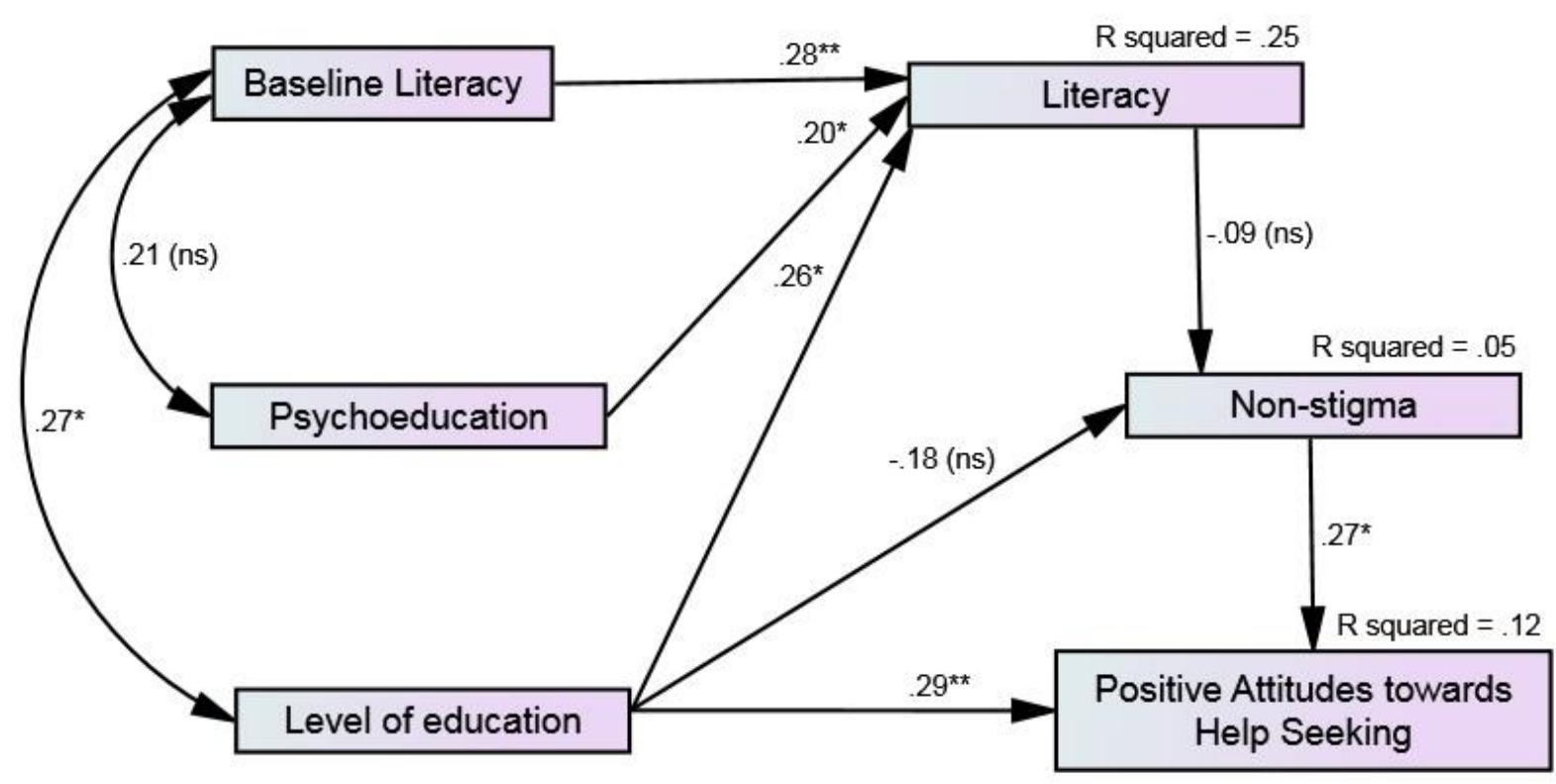

Figure 5. Trimmed model. ${ }^{*} p<.05, * * p<.01$ 


\section{Appendices}

\section{Appendix A}

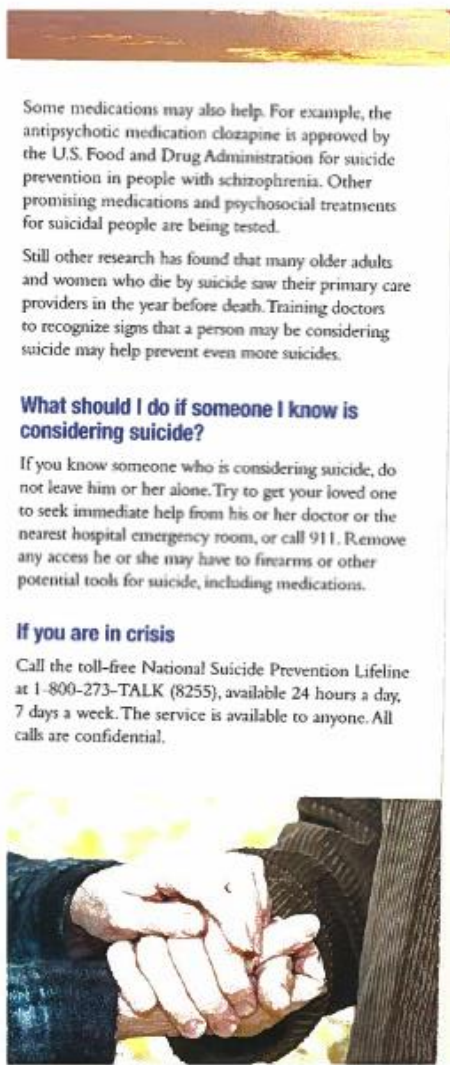

\section{Suicide in America}

Suicide is a major public health concern. Around 30,000 people die by suicide each year in the Unitod States. More people die by suicide each year than by homicide.

Suicide is tragic. But it is often preventable. Knowing the risk factors for suicide and who is at risk can help reduce the suicide rate.

Who is at risk for suicide?

Suicide does not discriminate. People of all genders ages, and ethnicities are at risk for suicide. But people most at risk tend to share certain characteristics. The main risk factors for suicide are:

- Depression, other mental disonders, or substance abuse disorder

- A prior suicide attempt

- Family history of a mental disorder or substance abuse

- Family history of suicide

Family violence, including physical or sexua

abuse

Having guns or other firearms in the home

- Incarceration, being in prison or jail

Being exposed to others' suicidal behavior, such as that of family members, peers, or media figures.

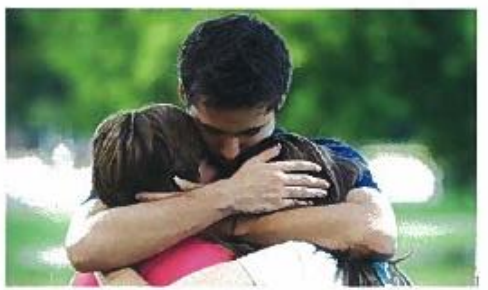

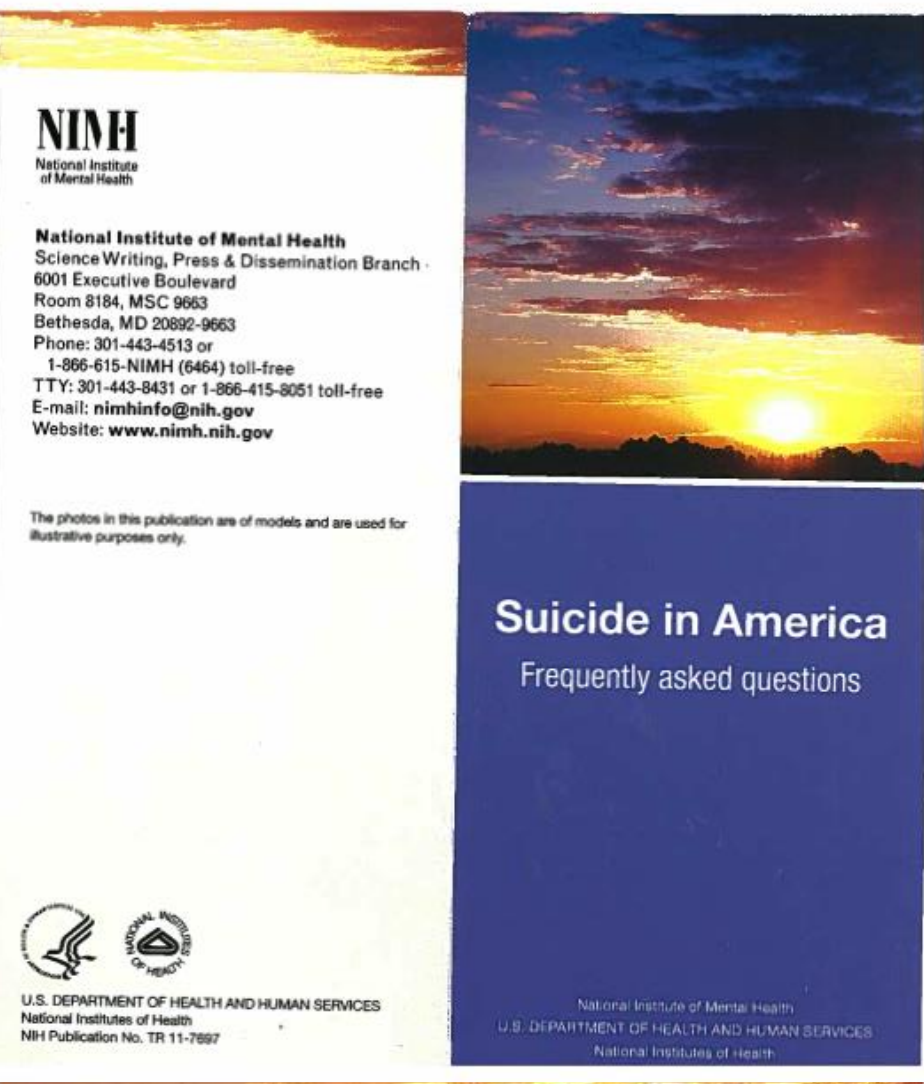

The risk for suicidal behavior also is associated with changes in brain chemicals called neurotranmitten, including serotonin, which is also associated with depression. Lower levels of serotonin have been found in the brains of people with a history of suicide attempts.

Many people have some of these risk factors but do not attempt suicide. Suicide is not a normal response to stress. It is however, a sign of extreme distress, not a harmless bid for attention

What about gender?

Men are more likely to die by suicide than women, but women are more likely to attempt suicide. Men are mose likely to use deadlier methods, such as firearms or suffocation. Women are more likely than men to attempt suicide by poisoning

\section{What about children?}

Children and young people are at risk for suicide.

Year after year, suicide remains one of the top three leading causes of death for young people ages 15 to 24

\section{What about older adults?}

Older adults are at risk for suicide, too in fast, white males age 85 and older consissently have the highest suicide rate than any other age and ethnic group.

What about different ethnic groups?

Among ethnicities, American Indians and Alaska Natives tend to have the highest rate of suicides. followed by non-Hispanic Whites. Hispanics send to have the lowest rate of suicides, while African Americans tend to have the second lowest rate.

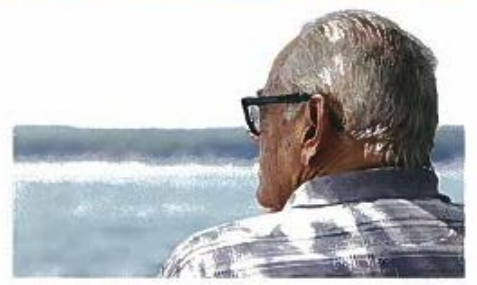

How can suicide be prevented?

Effective suicide prevention is based on sound research. Programs that work take into account people's risk factors and promote interventions For example, research has shown that mental and substance abuse disorders are risk factors for swicide. Therefore, many programs focus on treating these disonders in addition to addressing suicide risk specifically.

Psychotherapy, or "talk therapy" can effectively reduce suicide risk. One type is called cognitive behavioral therapy (CBT). CBT can help people learn new ways of dealing with stresful experiences by training them to consider alternative actions when thoughts of suicide arise. Another type of psychotherapy called dialectical behavior therapy (DBT) has been shown to reduce the rate of suicide among people with borderline personality disonder, a serious mental illness characterized by untable moods. relationships, self-image, and behwior A therapis trained in DBT helps a person recogrine when his or het feeling or actions are dinuptive or his or her feeling or action are disuptive or unhealthy, and teaches the skills needed to deal
better with upsetting situations. that are appropriate to specific groups of people 


\section{Appendix B}

Stretch It Out!

Strotch gently affer you warm up your muscles, and again after you cool down. Try doing the Suretches lived below Do not beunce or hold your breath when you stretch. Perform slow movements and stretch only as far as you feel comfortable.

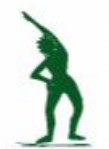

\section{Side Reach}

Reoch one orm over your head and to the side. and your thoulders stroight to the
side. Hold for 10 seconds and repeot on the other side.

\section{Wall Push}

lean your hands on a wall and away from the woll Bend one knee and point it toward the woll. Keep your back log straight with your foo hit and your loes pointed straigh repeat with the other log.

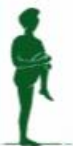

\section{Knee Pull}

Keep your heod, hips, and feet no stroight line. Pull one kneo oward your chest, hold for 10 ecconds, and then repeot with the

\section{Step Right This Way} Walking with proper form is very important. - Walk with your chin up and your shoulders slightly back.

- Let the heel of your foot touch the ground first, then roll your weight forward.

- Walk with your toes pointed forward.

- Swing your orms naturally as you walk.

\section{Wolk for Your Health}

$W^{\text {alking is one of the easiest ways for you }}$ To be physically active. This brochure provides you with general tips on how to creole

Walking is inexpensive, and you can walk almost anywhere and at any time. Walking may

- Give you more energy and slamino and lift your mood.

- Tone your muscles and strengthen your bones.

- Increase the number of calories your body uses.

- lower your risk of health problems, such as cholesterol, and type 2 diabetes.

- Give you an opportunity to actively socialize with friends and family.

The Weightcontrol Information Network (WIN) offers numerous free resources to help you begin working on your health and fitiness gools. Visit and share this ond other WiN moterials.

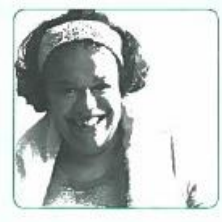

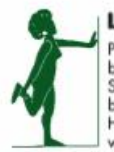

Leg Curl

pull your right foot loword your Pullocks with your right hand. Stand straight and keep your
bent knee pointing straight down. Hold for 10 seconds and ropec

\section{Hamstring Stretch}

Sit on a sturdy bench or hord surfoco so that one leg is stretched out on the oep your other loot hot on the surtace loel a strectch in the bock of your thigh, hold tor 10 seconds and then change

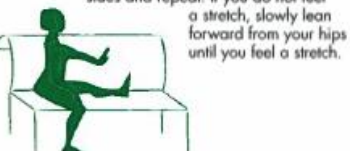

\section{About WIN}

The Weightcontrol Informotion Nerwork (WIN) is
a service of the National Institute of Diabetes and a service of the National institite of Diabetes and
Digestive and Kidney Diseases (NIDDK of the Nationol Intituvies of Health, which is the Federal Government's leod ogency responsible lor biomedicel research on nutrition and obesity

Publications produced by WIN ore reviewed by both is not copyrighted. WiN encourages users of this brochure to duplicate and distribule as many copies as desired. Kench with your loes pointing up.



Stort Wolking Now!

\section{Know Before You Go} - When you are physically active, do you have

- Are you 50 years old or older and not used is doing any moderote physical octivity? and remove it from your skin. hroughour the doy if you have a busy schedminutes long. Some physical activily is better

eep safery in mind as you plan when and nswer the following questions before you begin a walking progro

- Hos your health care provider told you thot
you hove heart trouble, diabetes, or osthma? -When you are physically active, do you have - Do you ofien feel faint or have dizzy spells?

- Do you feel extremely breathless after you have been physically octive?

- Has your health care provider told you that you have bone or joint problems, such as orthritis?

- Do you smoke?

- Do you have a health problem or physical reason not mentioned here that might keep you from starting a walking program?

If you answered "yes" 10 any of these questions, starting a walking program.

eave time in your busy schedule 10 follow a wolking program that will work for you. Keep

- Choose a sole place to wolk. Find a partner or group to wolk with you. Encourage and support eoch other in committing to wolking regularly
even if each of you has a different fitness level or wolks at a different pace.

- Wear shoes with proper arch support, a firm heel, and thick hlexible soles. They will cushion your leet ond absorb shock. Before you buy

- Wear clothes that will keep you dry and comfortable. Put on fabrics that absorb sweot

- Divide your wolk into three parts. Warm up slowly, then increose your speed to a brisk elevole your heart rate while still being able to speak comforlobly, concentrale, and breathe without effort. Cool down slowly.

- Stretch lightly affer warmup and cooldown.

- Spreod your walking evenly throughout the week. Try to wolk af least 3 days each week you cannot walk doily. Each week, add a few

Weight-control Information Network I WIN Way

MD 20892-3665

Phone: 202-828-1025

Fax: 202-828-1028

Filtive number: 1-877-940-4027

Email: WiNeinfo niddk nhth gov

Nit Publicotion No. 07-415.5

September 2004

Updoled Seplember 2010

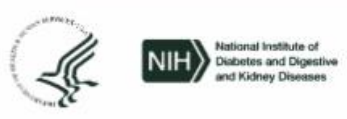

WIN

NiH..Turning Oiscovery into Health
- Break up your walk into mulfiple sessions ule. Make sure each session is at least 10

- To avoid stiff or sore muscles and joints, start gradually. Over several weeks, begin wolking faster, going further, and toking longer walks.

- Set gools and reward yourself.

- Keep track of your progress with a walking journal or log. Record date, fime, and distance.

Experts recommend at least 150 minules each week of moderately intense physical activity. schedule allows. Review the guide on the back of this brochure for suggestions on beginning and gradually building your wolking program. The more you walk, the more health benefits you may gain!

\section{Walk Safely}

- If you walk at down, dusk, or night, wear o reflective vest or brightly colored clothing

- Walk in a group when possible and carry some identification with you, as well as a way to contact someone if you need help.

- Notify family and triends of wolking time and route.

- Do not wear jewelry or

- Be oware of
your surrounding

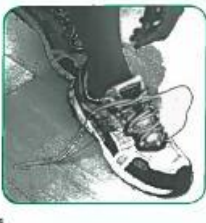




\section{Appendix C}

\section{Vignette.}

"For the last 3 months, José has not been able to shake the feeling of being gloomy and down. He lost his job a few months ago. He does not seem to enjoy anything. Playing sports, which once gave him pleasure, now seems empty and meaningless to him. He has lost touch with most of his old friends. He feels distant from his wife and family. He feels guilty about not being able to provide for his family, and in fact often has thoughts that they would be better off if he were dead. Last week, he tried to kill himself." 


\section{Appendix D}

\section{Literacy of Suicide Scale.}

1. José should tell others about his thoughts of suicide if he continues to have them $\mathrm{T} / \mathrm{F}$

2. Seeing a psychiatrist or psychologist may have helped prevent José from trying to kill himself $\mathrm{T} / \mathrm{F}$

3. José was probably psychotic before he tried to kill himself $\mathrm{T} / \mathrm{F}$

4. The risk of José committing suicide would have been higher if he had talked about suicide with his family or friends $\mathrm{T} / \mathrm{F}$

5. José will always be suicidal and entertain thoughts of suicide $\quad \mathrm{T} / \mathrm{F}$

6. José must have planned his suicide attempt in advance $\quad \mathrm{T} / \mathrm{F}$

7. José was among a very small segment of the population that ever has thoughts of suicide $\mathrm{T} / \mathrm{F}$

8. If assessed by a psychiatrist, José would be diagnosed as depressed $\quad \mathrm{T} / \mathrm{F}$

9. As a man, José is at a higher risk for dying by suicide than he would be if he were a woman $\mathrm{T} / \mathrm{F}$

10. José's risk for committing suicide would have been even greater if he were also an alcoholic $\mathrm{T} / \mathrm{F}$

11. It is possible that José may have changed his mind quickly about trying to kill himself, even though he had been thinking about it for awhile $\mathrm{T} / \mathrm{F}$

12. José was just trying to get attention when he cut his wrists $\mathrm{T} / \mathrm{F}$ 


\section{Appendix E}

\section{Social Distance Scale.}

1. Would you socially interact with José if he moved next door?
0
1
2
3
Definitely Not Probably Not Probably Definitely

2. Would you spend an evening socializing with José?
0
1
2
3
Definitely Not Probably Not Probably Definitely

3. Would you be friends with José?
0
1
2
3
Definitely Not Probably Not
Probably
Definitely

4. Would you work closely with José?
0
1
2
Definitely Not Probably Not
Probably
3
Definitely

5. Would you invite José into your home?
0
1
2
3
Definitely Not Probably Not Probably Definitely 


\section{Appendix F}

Stigma of Suicide Scale - Stigma subscale.

1. José's attempt to commit suicide was pathetic

$\begin{array}{ccccc}1 & 2 & 3 & 4 & 5 \\ \text { Strongly disagree } & \text { Disagree } & \text { Neither } & \text { Agree } & \text { Strongly agree }\end{array}$

2. José's attempt to commit suicide was shallow

$\begin{array}{ccccc}1 & 2 & 3 & 4 & 5 \\ \text { Strongly disagree } & \text { Disagree } & \text { Neither } & \text { Agree } & \text { Strongly agree }\end{array}$

3. José's attempt to commit suicide was immoral

$\begin{array}{ccccc}1 & 2 & 3 & 4 & 5 \\ \text { Strongly disagree } & \text { Disagree } & \text { Neither } & \text { Agree } & \text { Strongly agree }\end{array}$

4. José's attempt to commit suicide was vengeful

$\begin{array}{ccccc}1 & 2 & 3 & 4 & 5 \\ \text { Strongly disagree } & \text { Disagree } & \text { Neither } & \text { Agree } & \text { Strongly agree }\end{array}$

5. José's attempt to commit suicide was an embarrassment

$\begin{array}{ccccc}1 & 2 & 3 & 4 & 5 \\ \text { Strongly disagree } & \text { Disagree } & \text { Neither } & \text { Agree } & \text { Strongly agree }\end{array}$

6. José's attempt to commit suicide was irresponsible

$\begin{array}{ccccc}1 & 2 & 3 & 4 & 5 \\ \text { Strongly disagree } & \text { Disagree } & \text { Neither } & \text { Agree } & \text { Strongly agree }\end{array}$


7. José's attempt to commit suicide was stupid

$\begin{array}{ccccc}1 & 2 & 3 & 4 & 5 \\ \text { Strongly disagree } & \text { Disagree } & \text { Neither } & \text { Agree } & \text { Strongly agree }\end{array}$

8. José's attempt to commit suicide was cowardly

$\begin{array}{ccccc}1 & 2 & 3 & 4 & 5 \\ \text { Strongly disagree } & \text { Disagree } & \text { Neither } & \text { Agree } & \text { Strongly agree }\end{array}$




\section{Appendix G}

\section{Attitudes Toward Help-Seeking.}

1. If José was having a mental breakdown, his first inclination should have been to get professional attention.
0
1
2
3
Disagree
Partly Disagree Partly Agree
Agree

2. The idea of José talking about problems with a psychologist strikes me as a poor way to get rid of emotional conflicts.
0
1
Partly Disagree
2
3
Disagree
Partly Disagree Partly Agree
Agree

3. During this serious emotional crisis in José's life, I am confident that he could find relief in psychotherapy.
0
Disagree
1
2
3
Partly Disagree $\quad$ Partly Agree
Agree

4. There would be something admirable about José's attitude if he were willing to cope with his conflicts and fears without resorting to professional help.
0
1
2
3
Disagree
Partly Disagree
Partly Agree
Agree

5. I would want José to get psychological help if he were worried or upset for a long period of time.
0
1
2
3
Disagree
Partly Disagree
Partly Agree
Agree

6. José should seek psychological counseling in the future.
0
1
2
3
Disagree
Partly Disagree
Partly Agree
Agree

7. José is not likely to solve his emotional problems alone; he is likely to solve them with professional help.
0
1
2
3
Disagree
Partly Disagree
Partly Agree
Agree 
8. Considering the time and expense involved in psychotherapy, it would have doubtful value for José.
0
1
2
3
Disagree
Partly Disagree Partly Agree
Agree

9. José should work out his own problems; getting psychological counseling would be a last resort.
Disagree
1
2
3
Partly Disagree
Partly Agree
Agree

10. Personal and emotional troubles, like many things, tend to work out by themselves.

$\begin{array}{cccc}0 & 1 & 2 & 3 \\ \text { Disagree } & \text { Partly Disagree } & \text { Partly Agree } & \text { Agree }\end{array}$


Age:

Appendix $\mathrm{H}$

\section{Gender:}

Female

Male

Ethnicity:

Hispanic / Latino

If yes, please specify:

Mexican or Mexican American

Puerto Rican

Cuban

Central American

South American

Other:

Caucasian / White

African American / Black

Asian

American Indian

Pacific Islander

Biracial/Multiracial

Other:

\section{Religion:}

Christian

If yes, please specify:

Catholic

Protestant

Jewish

Muslim

Other:

What is your level of education?

0 to 2 years of school

3 to 5 years of school

6 to 8 years of school

9 to 11 years of school

High School Graduate

Some College

College Degree (Bachelor's Degree)

College Graduate School Degree (Master- or Doctorate-level 
What is your marital status?

Never married

Married

Separated

Divorced

Widowed

Common law / living together

In what country were you born?

Born in Mexico

Born in the United States

Born in a country other than the United States or Mexico

(please specify)

In what country was your mother born?

Born in Mexico

Born in the United States

Born in a country other than the United States or Mexico (please specify)

In what country was your father born?

Born in Mexico

Born in the United States

Born in a country other than the United States or Mexico

(please specify)

If you were born in another country, at what age did you first move to the United States? (Write N/A if you were born in the United States)

If you were born in another country, how long have you been living in the United States?

(Write N/A if you were born in the United States)

If you were born in another country, when did you last visit your country of origin? N/A, I was born in the United States

I have never visited my country of origin.

Over 5 years ago.

3 to 5 years ago.

2 to 3 years ago

1 to 2 years ago

6 to 12 months ago

Within the past 6 months. 


\section{Financial Strains \\ Global}

1) In the past 12 months, was there ever a time when your family did not have enough money to meet your family's daily needs? needs.

1. Yes, there were times when my family did not have enough money to meet my daily

2. No, my family always had enough money to meet our daily needs.

2) In the past 12 months, was there ever a time when your family did not have enough money to pay its monthly bills? bills.

1. Yes, there were times when my family did not have enough money to pay its monthly

2. No, my family always had enough money to pay its monthly bills.

\section{Basics}

3) In the past 12 months, was there ever a time when your family did not have enough money for food?

1. Yes, there were times when my family did not have enough money for food.

2. No, I always had enough money for food.

5) In the past 12 months, was your electricity, gas, or telephone turned off due to lack of payment?

1. Yes, there were times when my family did not have enough money to pay its utility bills.

2. No, my family always had enough money to pay its utility bills.

\section{Health care}

6) In the past 12 months, was there ever a time when your family did not have enough money for medical care for you or another family member?

1. Yes, there were times when my family did not have enough money for its medical care expenses.

2. No, my family always had enough money for its medical care expenses

7) In the past 12 months, was there ever a time when your family did not have enough money for your prescribed medicines for you or another family member? medicines.

1. Yes, there were times when my family did not have enough money for our prescribed

2. No, my family always had enough money for our prescribed medicines.

\section{What is your total yearly income for your household?}
(1) $\$ 0$. to $\$ 4,999$.
(2) $\$ 5,000$. to $\$ 14,999$.
(3) $\$ 15,000$. to $\$ 24,999$.
(4) $\$ 25,000$. to 34,999 .
(5) $\$ 35,000$. to $\$ 44,999$.
(6) $\$ 45,000$. to $\$ 60,000$.
(7) $\$ 60,000$. to $\$ 80,000$.
(8) Over $\$ 80,000$.
(9) Don’t know 
What language(s) do you usually speak at home?

Only Spanish

More Spanish than English

Both Equally

More English than Spanish

Only English

Other Language (please specify)

What language(s) do you usually speak with your friends?

Only Spanish

More Spanish than English

Both Equally

More English than Spanish

Only English

Other Language (please specify)

What was the language(s) you used as a child? (Before age 12)

Only Spanish

More Spanish than English

Both Equally

More English than Spanish

Only English

Other Language (please specify)

In general, what language(s) do you read and speak?

Only Spanish

More Spanish than English

Both Equally

More English than Spanish

Only English

Other Language (please specify)

In what language(s) do you usually think?

Only Spanish

More Spanish than English

Both Equally

More English than Spanish

Only English

Other Language (please specify) 
Appendix $\mathbf{J}$

Have you ever experienced the problem that José is experiencing?

Yes

No

If "Yes", did you... (check all that apply)

Tell a family member?

Tell a friend?

Tell a priest?

Tell a doctor?

Tell a psychologist or other mental health professional? 


\section{Appendix K}

\section{Past/current suicidal ideation and behavior and exposure to suicide.}

1. How often have you thought about killing yourself in your lifetime? (Mark only one):
Never
Rarely (1 time)
Sometimes (2 times)
Often (3-4 times)
Very often (5 or more times)

2. How often have you thought about killing yourself in the past week? (Mark only one):

Never
Rarely (1 time)
Sometimes ( 2 times)
Often (3-4 times)
Very often (5 or more times)

3. How many times have you ever attempted to kill yourself? (Mark only one):

Never
Once
Twice
Three or more times

4. If you have previously attempted suicide, how much did you wish to die during your most serious attempt?

I have never attempted suicide.

My wish to die was low.

My wish to die was moderate.

My wish to die was high.

Please check all that apply:

I have observed suicide in a movie or TV show

I have seen a documentary on suicide

I have had a colleague who attempted or died by suicide

I have provided services to someone who attempted or died by suicide

I have had an acquaintance who attempted or died by suicide

I have had a relative who attempted or died by suicide

I have had a close friend who attempted or died by suicide

I have lived with someone who attempted or died by suicide

I have attempted suicide 
IRB Approval.

Appendix L

\section{UN IVERSITY O F ARKANSAS}

Office of Research Compliance Institutional Review Board

February 17, 2015

MEMORANDUM

TO:

Aubrey Dueweke

Ana Bridges

FROM:

Ro Windwalker

IRB Coordinator

RE:

New Protocol Approval

IRB Protocol \#:

15-01-451

Protocol Title:

Suicide and Help-Seeking

Review Type:

$\square$ EXEMPT $\triangle$ EXPEDITED $\square$ FULL IRB

Approved Project Period: $\quad$ Start Date:02/17/2015 Expiration Date: 02/03/2016

Your protocol has been approved by the IRB. Protocols are approved for a maximum period of one year. If you wish to continue the project past the approved project period (see above), you must submit a request, using the form Continuing Review for IRB Approved Projects, prior to the expiration date. This form is available from the IRB Coordinator or on the Research Compliance website (https://vpred.uark.edu/units/rscp/index.php). As a courtesy, you will be sent a reminder two months in advance of that date. However, failure to receive a reminder does not negate your obligation to make the request in sufficient time for review and approval. Federal regulations prohibit retroactive approval of continuation. Failure to receive approval to continue the project prior to the expiration date will result in Termination of the protocol approval. The IRB Coordinator can give you guidance on submission times.

This protocol has been approved for $\mathbf{1 0 0}$ participants. If you wish to make any modifications in the approved protocol, including enrolling more than this number, you must seek approval prior to implementing those changes. All modifications should be requested in writing (email is acceptable) and must provide sufficient detail to assess the impact of the change.

If you have questions or need any assistance from the IRB, please contact me at 109 MLKG Building, 5-2208, or irb@uark.edu. 